Check for updates

Cite this: RSC Adv., 2020, 10, 42838

\title{
ZnO nanostructured materials for emerging solar cell applications
}

\author{
Arie Wibowo, D *ab Maradhana Agung Marsudi, ${ }^{a}$ Muhamad Ikhlasul Amal, ${ }^{c}$ \\ Muhammad Bagas Ananda, ${ }^{a}$ Ruth Stephanie, (D) ${ }^{a}$ Husaini Ardy (D) ${ }^{a}$ \\ and Lina Jaya Diguna (iD *d
}

Zinc oxide $(\mathrm{ZnO})$ has been considered as one of the potential materials in solar cell applications, owing to its relatively high conductivity, electron mobility, stability against photo-corrosion and availability at low-cost. Different structures of $\mathrm{ZnO}$ materials have been engineered at the nanoscale, and then applied on the conducting substrate as a photoanode. On the other hand, the $\mathrm{ZnO}$ nanomaterials directly grown on the substrate have been attractive due to their unique electron pathways, which suppress the influence of surface states typically found in the former case. Herein, we review the recent progress of $\mathrm{ZnO}$ nanostructured materials in emerging solar cell applications, such as sensitized and heterojunction architectures, including those embedded with promising perovskite materials. The remarkable advancement in each solar cell architecture is highlighted towards achieving high power conversion efficiency and operational stability. We also discuss the foremost bottleneck for further improvements and the future outlook for large-scale practical applications.

Received 8th September 2020

Accepted 3rd November 2020

DOI: $10.1039 / d 0 r a 07689 a$

rsc.li/rsc-advances

\section{Introduction}

Emerging solar cell technologies that use complex and advanced materials, such as perovskite, dye-sensitized, organic, quantum dot and multijunction, were born to answer the challenges for conversion efficiency and durability. None of the developed solar cell technology has closely achieved the theoretical energy conversion limit to $90 \%$. The primary cause of the inefficiency of solar cells is related to the energy bandgap, as well as the transmission and thermalization losses. This is strongly related to the properties of the active material, including their defects. In addition, the intrinsic stability of these materials affects the lifetime or durability of the solar cells systems. The desired properties of the charge transport materials for solar cells application are ideal energy levels that correspond to the high absorption efficiency of the solar spectrum, high carrier mobility, good conductivity, and efficient extraction of the excited carriers.

\footnotetext{
${ }^{a}$ Material Science and Engineering Research Group, Faculty of Mechanical and Aerospace Engineering, Institut Teknologi Bandung, Jl. Ganesha 10, Bandung, 40132, Indonesia. E-mail: ariewibowo@material.itb.ac.id

${ }^{b}$ Research Center for Nanoscience and Nanotechnology, Institut Teknologi Bandung, Jl. Ganesha 10, Bandung, 40132, Indonesia

${ }^{c}$ Research Center for Metallurgy and Materials, The Indonesian Institute of Sciences, Puspitek, Serpong, Banten 15314, Indonesia

${ }^{d}$ Department of Renewable Energy Engineering, Universitas Prasetiya Mulya, Kavling Edutown I.1, Jl. BSD Raya Utama, BSD City, Tangerang 15339, Indonesia. E-mail: lina.diguna@prasetiyamulya.ac.id
}

ZnO materials, one of the group II-VI binary compound semiconductors, have been considered in solar cell applications due to their stability, high conductivity, high electron affinity and excellent electron mobility. Fig. 1 illustrates the advantages of $\mathrm{ZnO}$ as an active material for solar cell applications. ZnO materials are wide bandgap semiconductors with a band gap of 3.1-3.3 eV that absorb light only in the UV region. ZnO can also be coupled with smaller energy gap materials, such as dye sensitizers, organic polymers, and smaller band gap semiconductors, to extend their light absorption to the visible region. The bulk $\mathrm{ZnO}$ has been reported to have an exciton Bohr radius $\left(a_{\mathrm{B}}\right)$ of $2.34 \mathrm{~nm} .^{1}$ This is comparable to the significant confinement effects, experimentally observed for the solution phase synthesized $\mathrm{ZnO}$ particles with the particle radii of less than about $4 \mathrm{~nm}$, due to the relatively small effective masses for $\mathrm{ZnO}$, i.e., $m_{\mathrm{e}}=0.26 m_{0}, m_{\mathrm{h}}=0.59 m_{0}$ and $m_{0}$ is the free electron mass. ${ }^{2}$ The high electron mobility of $\mathrm{ZnO}$ makes this material attractive for solar cell application, 205-300 for bulk ${ }^{3,4}$ and 1000 $\mathrm{cm}^{2} \mathrm{~V}^{-1} \mathrm{~s}^{-1}$ for nanorod $\mathrm{ZnO} .{ }^{5}$ These values are relatively high compared to those of the commonly used $\mathrm{TiO}_{2}$, i.e., $0.1^{-4} \mathrm{~cm}^{2}$ $\mathrm{V}^{-1} \mathrm{~s}^{-1}{ }^{6}$ Moreover, the electron diffusion coefficient is 5.2 for bulk and $1.7 \times 10^{-4} \mathrm{~cm}^{2} \mathrm{~s}^{-1}$ for the nanoparticulate film $\mathrm{ZnO}^{7}$ Conversely, in the bulk and nanoparticulate film $\mathrm{TiO}_{2}$, the electron diffusion coefficient becomes 0.5 and $10^{-8}-10^{-4} \mathrm{~cm}^{2}$ $\mathrm{s}^{-1}$, respectively. ${ }^{8} \mathrm{ZnO}$ is also well-known as a polymorph, having a different type of structure depending on the synthesis method. The nanomorphology of $\mathrm{ZnO}$ comprise nanospheres, nanowires, nanorods, nanoflower, nanotubes, nanocrystals, and 3D nanostructures (core-shell). These excellent attributes 


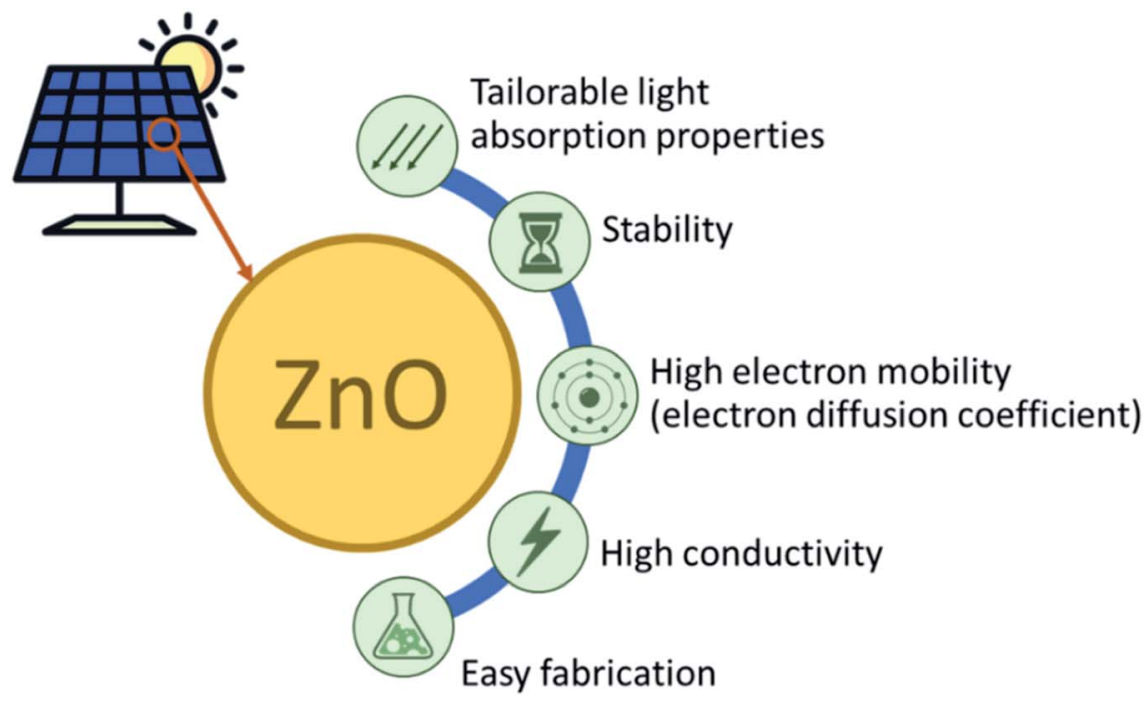

Fig. 1 The merits of $\mathrm{ZnO}$ for solar cell application.

have made $\mathrm{ZnO}$ widely applied in many areas, such as sensors, surface coating, porous ceramics, photodetectors, nanopiezoelectric, and supercapacitors, in addition to solar cells. There are also many available methods to prepare $\mathrm{ZnO}$ nanomaterials from different pathways (biological/physical/ chemical), such as green synthesis using microorganisms, hydrothermal, sol-gel, electrochemistry, inkjet printing, atomic layer deposition, and sputtering technique.

In this review, the latest application of $\mathrm{ZnO}$ in thirdgeneration solar cell technologies is thoroughly discussed. Different solar cell architectures, i.e., sensitized solar cells and heterojunctions solar cells, including those embedded with promising perovskite materials, will be reviewed in accordance with the influence of the synthesis strategies on the $\mathrm{ZnO}$ properties. These approaches include the application of different nanostructures of $\mathrm{ZnO}$, deposition and post-treatment method, and inclusion of dopant materials (Fig. 2). The discussion will be concluded by the proposal of future strategies to improve the current achievements Fig. 2.

\section{Emerging solar cell application}

\subsection{Sensitized solar cells}

Dye-sensitized solar cells (DSSCs) were first proposed by O'Regan and Grätzel in 1991, and have attracted great interest as an alternative to conventional silicon solar cells. The fabrication is straightforward and low-cost, with good long-term stability and energy conversion efficiency exceeding $10 \% .{ }^{9} \mathrm{Ru}-$ based dyes are utilized as photosensitizers that are attached to the mesoporous metal oxide photoelectrode with large

\section{Nanostructured ZnO in Emerging Solar Cells Application}

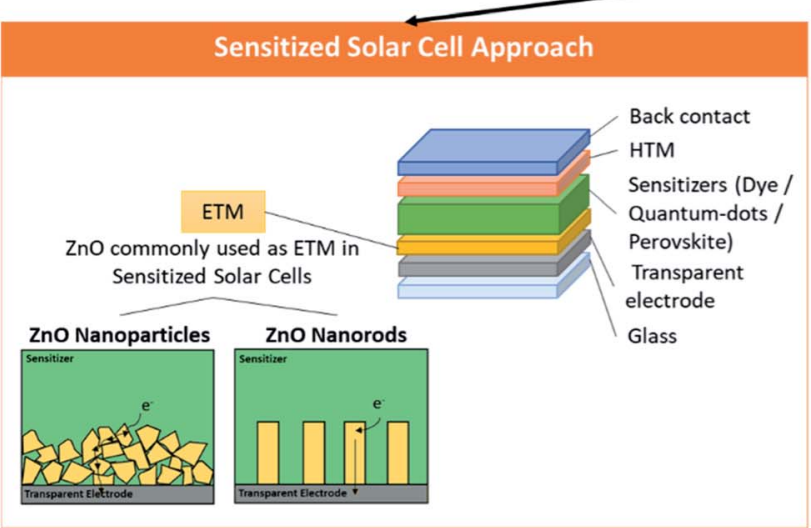

\section{Bulk Heterojunction Solar Cell Approach}

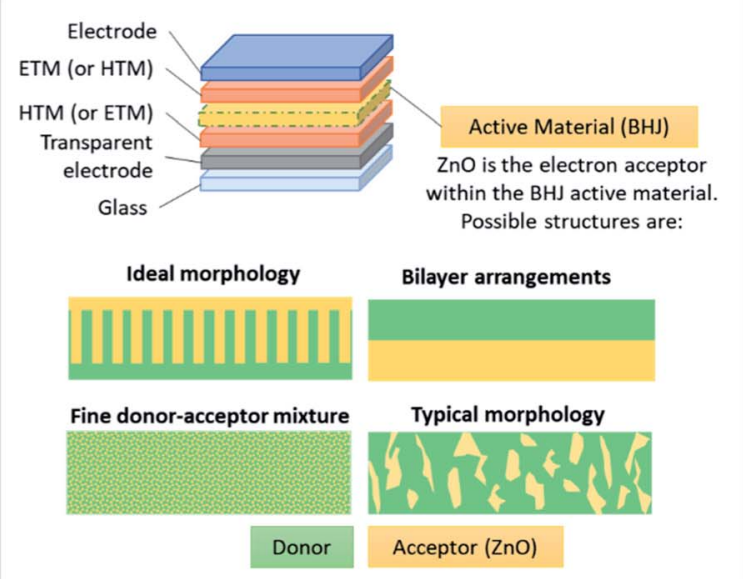

Fig. 2 Nanostructured $\mathrm{ZnO}$ in emerging solar cell applications. 
surface areas, and absorb solar energy efficiently. The electrons injected by the optically excited dye into the metal oxide conduction band diffuse across the semiconductor film layer, and reach the back contact. Redox couples diffuse in solution, which are in turn reduced at the counter electrode, and regenerate the oxidized dye. Because of the sensitizers, the high expense to provide the typical dyes (N3, N719) has encouraged the alternative use of narrow band gap semiconductor quantum dots (QDs), owing to their size-tunable optical properties to match the solar spectrum. Moreover, QD-sensitized solar cells (QDSCs) have the capability of producing multiple electronhole pairs per photon quantum yields greater than 1 through impact ionization. ${ }^{\mathbf{1 0 - 1 2}}$ In the early studies, QD-sensitized solar cells showed performances well below the expectation, where the achieved efficiency in two-electrode configurations was below $1 \% .^{13,14}$ Later, the efficiency of $2.7 \%$ reported by Diguna et al. in 2007 brought about a resurgence in the development of QDSCs. ${ }^{15}$ The different morphologies of the photoanode have also been considered to enhance the light-harvesting efficiency, such as the inverse opal due to its large interconnected pores for better penetration of the dye and photon confinement at a wavelength near the photonic band gap for the significant enhancement of dye absorption. ${ }^{16}$ In the following sections, the application of various $\mathrm{ZnO}$-nanostructured materials and their recent progress in DSSCs, PSSCs, and QDSCs are discussed in detail.

2.1.1 Dye-sensitized solar cells. In 1980, Matsumura et al. reported $2.5 \%$ energy conversion efficiency under monochromatic light at $562 \mathrm{~nm}$ using ZnO porous disks sensitized with rose bengal. ${ }^{17}$ The efficiencies for the nanoporous $\mathrm{ZnO}$ thin film were then reported to reach as high as $2 \%$ under $56 \mathrm{~mW}$ $\mathrm{cm}^{-2}$ illumination with the ruthenium-complex dye, ${ }^{18}$ and $2.5 \%$ under $99 \mathrm{~mW} \mathrm{~cm}^{-2}$ illumination with the mercurochrome sensitizer. ${ }^{19}$ The mercurochrome dye was bonded to the $\mathrm{ZnO}$ surface in a way that is similar to $\mathrm{TiO}_{2}$ through the carboxylate linkage. On the other hand, the different adsorption of the ruthenium-based dye caused the typically poor performance of $\mathrm{ZnO}$ compared to $\mathrm{TiO}_{2}$. The formed agglomerates of $\mathrm{Zn}^{2+}$ and the ruthenium dye molecules during dye adsorption were reported to fill up the nanopores of the $\mathrm{ZnO}$ electrode, and act as an insulating layer blocking the injected electrons from the dye molecules to the semiconductor. ${ }^{\mathbf{2 0 , 2 1}}$ The isoelectric point of $\mathrm{ZnO}$ is $\sim 9$ and that of $\mathrm{TiO}_{2}$ is $\sim 6$, implying that $\mathrm{ZnO}$ is more fundamental than $\mathrm{TiO}_{2}$. Therefore, the $\mathrm{ZnO}$ electrode has poor chemical stability in the presence of an acidic dye. ${ }^{22}$ The deprotonation of the carboxyl groups of the ruthenium dye made the dye solution relatively acidic, and can etch $\mathrm{ZnO}$ surfaces during the dye adsorption. The dissolution of $\mathrm{ZnO}$ by the acidic carboxylic groups of the dyes takes place at the crystal surface. This leads to the formation of $\mathrm{Zn}^{2+} /$ dye complexes, and thus prevents the efficient electron injection. A nanoporous ZnO electrode sensitized with ruthenium bipyridyl complex has been reported with an efficiency of up to $5 \%$. This was achieved by suppressing dye aggregation and $\mathrm{Zn}^{2+} /$ dye complex formation with the addition of basic $\mathrm{KOH}$ to the dye solution, and by applying pressure and excluding organic additives in the $\mathrm{ZnO}$ film preparation for better interfacial kinetics. ${ }^{23,24}$ The photoelectrochemical characteristics of the $\mathrm{ZnO}$ electrode strongly depended on the electrode morphology, such as the size, the shape of the particles and the porosity, whereas the $8 \mathrm{~mm}$ thick $\mathrm{ZnO}$ film consisting of $150 \mathrm{~nm}$ spherical particles was found to exhibit efficient electron transport in the nanostructured electrode with small recombination losses. ${ }^{25}$

The traditional nanoparticle film in DSSCs effectively provided a large surface area for the adsorption of lightharvesting dye molecules. However, the electron transport through the nanoparticle film was based on trap-limited diffusion, a slow mechanism that limited the device efficiency, especially at longer wavelengths. Therefore, an array of oriented 1D nanostructures, such as nanowires, nanorods and nanotubes, was later introduced as a promising solution to increase the electron diffusion length in the anode. The aspect ratio (length divided by diameter) of the nanowires may be up to 1000 , while that of the nanorods is much smaller, usually less than ten depending on the synthesis method and condition. In 2005, the $\mathrm{ZnO}$ nanowire photoanode with an array length between 20-25 $\mu \mathrm{m}$ and a surface area of up to one-fifth of a nanoparticle film was synthesized using a seeded growth process. The ZnO quantum dots as a 10-15 nm thick film was initially deposited onto the FTO substrate by dip coating. Later, wires were grown from these nuclei through thermal decomposition of the zinc complex. With the sensitization of the ruthenium dye, it demonstrated $1.5 \%$ efficiency at one sun. ${ }^{26}$ In the same studies, the electron injection from the photoexcited ruthenium dyes into nanowires and nanoparticles was evaluated by using femtosecond transient absorption spectroscopy. The resulting bi-exponential kinetics of the nanowires (time constants of $<250$ fs and around $3 \mathrm{ps}$ ) confirmed the faster electron injection relative to the nanoparticles with a triexponential response (time constants of $<250 \mathrm{fs}, 20 \mathrm{ps}$ and $200 \mathrm{ps}$ ). The Core-shell concept was then applied to the $\mathrm{ZnO}$ nanowire photoanode by coating $\mathrm{ZnO}$ nanowires with the thin shell of amorphous $\mathrm{Al}_{2} \mathrm{O}_{3}$ or anatase $\mathrm{TiO}_{2}$ by atomic deposition. ${ }^{27} \mathrm{~A}$ very thin alumina shell acted as a tunnel barrier that improved the $V_{\text {oc }}$ by impeding recombination, but blocked electron injection as it became thicker. On the contrary, titania shells were found to suppress the rate of recombination and improve the open-circuit voltage and fill factor, in which the shell thickness of 10-25 $\mathrm{nm}$ caused a dramatic increase in efficiency by up to $2.25 \%$ under one sun.

The photovoltaic properties of the $\mathrm{ZnO}$ nanorods were reported to be dependent on not only the rod size, but also on their orientation. ${ }^{28}$ Vertically aligned ZnO nanorods with N179 sensitization exhibited very low power conversion efficiency, i.e., $0.22 \%$ and $0.09 \%$ for hydrothermally grown and vapor deposited $\sim 3.5 \mu \mathrm{m}$-length $\mathrm{ZnO}$ nanorods. ${ }^{29}$ Modification on the $\mathrm{ZnO}$ nanorod surface with gold nanoparticles formed a Schottky barrier, and then blocked the electron transfer back from $\mathrm{ZnO}$ to the N719 dye and electrolyte, thus increasing the efficiency up to $1.2 \% .^{30}$ Doping the $\mathrm{ZnO}$ nanorods with $\mathrm{Al}$ also improved the performance of the N719-sensitized $\mathrm{ZnO}$ nanorods from $0.05 \%$ to $1.34 \% .{ }^{31}$ Here, the occupation of the trivalent $\mathrm{Al}^{3+}$ in the divalent $\mathrm{Zn}^{2+}$ ion site increased the electron concentration and thus the electrical conductivity, allowing electrons to move 
easily into the $\mathrm{Al}$-doped $\mathrm{ZnO}$ conduction band. Chemically etching the center part of the electrochemically deposited $\mathrm{ZnO}$ nanorods produced a $\mathrm{ZnO}$ nanotube array. The employment of the $5.1 \mu$ m-length ZnO nanotube as a photoanode with N719 sensitization showed an efficiency of $1.18 \% .^{32}$ On the other hand, ZnO nanotube photoanodes templated by an anodic aluminium oxide exhibited an efficiency of $1.6 \%$ under AM 1.5 illumination. ${ }^{33}$ Combined with atomic layer deposition to conformally coat the nanotube pores, the design could provide a direct path for charge collection over tens of micrometers thickness, indicated by the exceptional photovoltage of $739 \mathrm{mV}$ and fill factors of 0.64. Unfortunately, the low photocurrent caused by insufficient light harvesting due to the small roughness factor and photoanode reflectivity/scattering (light coming from the counter electrode side) limited the overall efficiency. The increase of the surface area was required to further improve the energy conversion efficiency.

The dye in DSSCs also plays a critical role in enhancing the PCE. A compatible dye in the ZnO-based DSSCs will improve the electron injection efficiency. The enhancement of the electron injection efficiency depends on the electronic coupling and relative energy levels between the dye and the semiconductor, the lifetime of the dye, and ultimately on the density of the electron-accepting state (DOS) in the semiconductor. The electronic coupling between the dye and semiconductor relies on the selection of the dye group for the appropriate semiconductor. The dyes shall be identified or synthesized, for which the LUMO (Lowest Unoccupied Molecular Orbital) and HOMO (Highest Occupied Molecular Orbital) levels match, respectively, with the conduction band energy levels and the valence band energy levels of the semiconductor. The lifetime of the excited state is a fundamental property of the photosensitizer. The dye with longer life in the excited state is expected to be easier for charge transfer. ${ }^{34}$

In contrast to $\mathrm{TiO}_{2}, \mathrm{ZnO}$ is not compatible with the $\mathrm{Ru}$ dye due to its more alkaline nature, making it susceptible to low $\mathrm{pH}$ conditions. The $\mathrm{Ru}$ dye also removes $\mathrm{Zn}^{2+}$ ions from the $\mathrm{ZnO}$ lattice. The improper immersion duration of the $\mathrm{ZnO}$ film in the ruthenium dye could lead to a lower efficiency for the DSSC due to $\mathrm{ZnO}$ film release, reduction in the number of free electrons, promotion of the recombination process, and transformation of the porous film to a denser one. ${ }^{34,35}$ In some recently reported research studies (Table 1), metal-free dyes such as indoline dyes, D205 and D149, ${ }^{36}$ heptamethine-cyanine dye (KFH-3), ${ }^{37}$ $\mathrm{C} 220^{38}{ }^{38}$ carbazole dyes, ${ }^{39}$ anthocyanins, ${ }^{\mathbf{4 0}}$ and Xanthenes ${ }^{\mathbf{4 1}}$ were found to be the right-choice for this purpose. Recent studies by Chang et al. and Lin et al. have shown that dyes with relatively lower acidity (indoline dye coded D149) show a relatively good compatibility with ZnO. Both types of research studies conducted found that an efficiency higher than $5 \%$ can be achieved for the flexible $\mathrm{ZnO}$-based DSSC. ${ }^{\mathbf{4 2 , 4 3}}$

In a more recent study, several efficient metal-free organic sensitizers were developed by Selopal et al. called B18, BTD-R, and CPTD-R for ZnO-based DSSCs. The B18 dye provides better photovoltaic properties than the other two dyes in the hierarchically structured $\mathrm{ZnO}$ and commercial $\mathrm{TiO}_{2}$ due to the higher electron injection potential and better light harvesting.
Table 1 The effect of the $\mathrm{ZnO}$ nanostructure, dye type, and doping type on the photovoltaic performance of $\mathrm{ZnO}$ based-DSSCs

\begin{tabular}{lllll}
\hline ZnO nanostructure & Dye & Doping & PCE (\%) & Ref. \\
\hline Nanorods & Crystal violet & La & 0.36 & 49 \\
Nanoflower & N719 & Li & 1.23 & 48 \\
Nanoparticles & Mercurochrome & $\mathrm{Ag}$ & 2.02 & 47 \\
Nanospheres & N719 & In & 2.7 & 51 \\
Hollow spheres & N719 & - & 3.28 & 53 \\
Nanorods & N719 & - & 3.75 & 54 \\
Nanoparticles & N719 & Iodine & 4.01 & 45 \\
& D205 & & 4.44 & \\
Pomegranate & N719 & - & 4.35 & 53 \\
Nanoparticles & CYC-B1 & - & 5.4 & 55 \\
Nanosheets & N3 & B & 6.75 & 46
\end{tabular}

The TCD/TVD results showed that the device with dye B18 had a better $\tau R$ and negligible shift in dye-sensitive photoanode CB compared to the CPTD-R and BTD-R dye-based devices. ${ }^{44}$

Another way to improve electron transport in the $\mathrm{Zn}$ photoanode, which also enhances cell efficiency, is to add dopants to the $\mathrm{ZnO}$ film. Dopants will fill the holes in the cell, thus increasing the recombination injected electron in the semiconductor. ${ }^{34}$ Several materials such as iodine, ${ }^{45} \mathrm{~B},{ }^{46} \mathrm{Ag},{ }^{47} \mathrm{Li},{ }^{48}$ $\mathrm{La},{ }^{49} \mathrm{Sr},{ }^{50} \mathrm{In},{ }^{51}$ and $\mathrm{Nd}^{52}$ could be doped into the semiconductor film of $\mathrm{ZnO}$, according to some reports. Zhao et al. used iodinedoped ZnO-based as a photoanode in dye-sensitized solar cells with indoline D205 and N719 as the sensitizers. The result demonstrated that iodine-doping boosts the efficiencies compared to the cells without iodine. The efficiencies of the D205-I-ZnO based DSSC and N719-I-ZnO based DSSC were enhanced by $20.3 \%$ and $17.9 \%$, respectively. ${ }^{45}$ Mahmood and Park reported a cell fabricated with $\mathrm{ZnO}$ nanosheets doped with boron and using the N3 dye as a sensitizer, achieving a significant enhancement in PCE $(6.75 \%)$ in contrast to the undoped ZnO nanosheets $(2.62 \%)$ and BZO films only including nanosized crystallites (3\%). ${ }^{\mathbf{4 6}}$ The work from Lanjewar et al. revealed that upon doping with $\mathrm{Ag}$, the band gap is sharply reduced and the resulting Ag:ZnO photoelectrode could absorb the visible light range to a great extent. The most massive reduction in the band gap was achieved from $3.28 \mathrm{eV}$ for the pure $\mathrm{ZnO}$ film to $2.65 \mathrm{eV}$ for $\mathrm{Ag}: \mathrm{ZnO}$ with $10.3 \mathrm{wt} \%$ doping with the enhancement of PCE from $0.55 \%$ to $2.02 \% .{ }^{47}$ In a very recent study, Aksoy and collaborator investigated the addition of $\mathrm{Li}$ into $\mathrm{ZnO}$ powder using N719 dye for dye-sensitized solar cells. The result suggested that the nanoflower morphology was formed, and the efficiency of the cells rise to the value of $1.23 \%$. The enhanced efficiency was associated with the change in the morphology, and an improvement in the crystallinity in Li-doped $\mathrm{ZnO}$ based DSSCs. ${ }^{48}$ Research conducted by Goel and co-worker demonstrated that the La-doped ZnO-based nanopowder solar cell exhibited superior photovoltaic performance when compared to the pure ZnO-based cell. The light harvesting efficiency $(\eta)$ increased from $0.20 \%$ to $0.36 \%$ on doping with La. ${ }^{49}$ In a study by Chava et al. using Indium-doped $\mathrm{ZnO}$, the maximum photoconversion efficiency of $2.7 \%$ was achieved on $0.2 \mathrm{In}-\mathrm{ZnO}$ 
photoelectrode films that consisted of nanosized crystallites and aggregated spheres of nano-crystallites.

The enhancement in the performance of DSSCs with 0.2 InZnO films was attributed to the strong light scattering phenomenon of aggregated spheres within the photoelectrode film, the pore size of the aggregates, which offers a more porous structure for dye infiltration and electrolyte diffusion. ${ }^{51}$

2.1.2 Quantum dots-sensitized solar cells. $\mathrm{ZnO}$ nanostructured materials have been explored as a photoanode in sensitized solar cells with narrow semiconductor quantum dots as an alternative light absorber that replaces dye molecules. The properties of quantum dots (QDs) and photoanode films and the interconnectivity between them play significant roles in the device performance. The implementation of a particular fabrication method to obtain specific characteristics may lead to some challenging issues. Pre-synthesized $\mathrm{ZnO}$ nanomaterials usually are applied to a conductive glass substrate by using squeegee methods. ${ }^{56}$ On the other hand, QDs could be synthesized and later adsorbed on the photoanode or directly in situ grown on the photoanode. ${ }^{12,57,58}$ This pre-synthesized method of QD permits greater control over the size, shape and surface properties of QD. However, the resulting QD seems to be a monolayer, delicately adsorbed on the photoanode surface. Thus, appropriate crosslinking molecules are usually required to deposit QDs properly on the photoanode. The deposition of both pre-synthesized ZnO materials and QDs may affect the contact between the semiconductor films and conductive glass, or between the semiconductor films and QDs. The ultrasonic spray pyrolysis method in depositing both $\mathrm{ZnO}$ particles and CdS QDs on the conductive glass has been proposed to create a good contact for efficient electron transport from CdS QDs to a conductive glass via $\mathrm{ZnO}$ photoanode, as shown by the increased short circuit current density. ${ }^{59}$ On the other hand, the in situ growth method might also be implemented to grow the ZnO photoanode directly on the substrate ${ }^{60}$ and/or QDs deposition on the $\mathrm{ZnO}$ surface. ${ }^{61}$ This method may provide a good contact of the $\mathrm{ZnO} /$ substrate interface and more extensive, uniform deposition of QDs in the entire photoanode.

Different ZnO structures have also been pursued to achieve specific features, such as better electron transport than those obtained in nanoparticles. One-dimensional (1D) structures such as nanorods, nanowires, and nanotubes, had vertically aligned electrical pathways and reduced particle-to-particle hopping of electrons usually found in the nanoparticle network, which are expected to increase the efficiencies of those photoelectrical devices. Modification on the $\mathrm{ZnO}$ nanorod, i.e., taper-like arrays, could minimize the charge transfer resistance, thus increasing the short current circuit and conversion efficiency consequently for the case of nitrogen-doped graphene QDs. ${ }^{62}$ Moreover, the efficiencies of the ZnO nanorod array devices are limited by their low light-harvesting ability. Nanotubes have a larger surface area than nanorods of similar length and diameter. $\mathrm{ZnO}$ nanotube arrays have been proved to have a superior ability as compared with $\mathrm{ZnO}$ nanorod arrays due to the excellent light scattering efficiency on account of their 1D tubular nature. ${ }^{63}$ Taking into account the critical role of the QDS interfaces in carrier relaxation, ${ }^{64}$ interfacial engineering (such as surface modification) has reported over one decade in suppressing surface defects, leading to smooth electron transfer and thus improving the photovoltaic performance of the QDsensitized $\mathrm{TiO}_{2}$ solar cells. ${ }^{15,56,58}$ The similar approach has also been introduced on the CdS/CdSe quantum dot co-sensitized $\mathrm{ZnO}$ photoanode by MnS passivation layer to suppress charge recombination at the photoelectrode/electrolyte interface, and also enhance the light-harvesting capability in terms of both absorbance intensity and absorption range. ${ }^{65}$ One option to increase the solar cell performance is by structure architecture, enabling the light scattering and thus, the light-harvesting efficiency. $\mathrm{ZnO}$ hollow microspheres have been found to generate light scattering and thus improve the power conversion efficiency of the $\mathrm{Zn}_{x} \mathrm{Cd}_{1-x} \mathrm{Se}$ QDSSC. ${ }^{66}$ On the other hand, this hollow structure may also lead to the defects located at the surface. To tackle this issue, the $\mathrm{TiO}_{2}$ passivation layer on the hollow microsphere surface has been reported recently to improve the CdSe/CdS QDSSC performance. The improvement not only produced better light harvesting, but also reduced the charge recombination and lengthened the electron lifetime. ${ }^{67}$ QDs have a unique capability of producing multiple electronhole pairs per photon quantum yields greater than 1 through impact ionization. ${ }^{\mathbf{1 0} 11}$ The attachment of QDs on the $\mathrm{ZnO}$ surface has been reported to possibly speed up carrier relaxation in the QDs, which is an essential factor for hot-carrier energy harvesting via multiple electron generation and hot electron transfer, depending on the exact linker molecules. ${ }^{68}$ Although an external photocurrent quantum efficiency of more than $100 \%$ has been reported for the hererojunction $\mathrm{ZnO} / \mathrm{PbSe}$ QD solar cell, ${ }^{69}$ to the best of our knowledge, there are no reports on QDSSCs yet.

Besides the design of the photoanode in terms of its semiconductor properties, interfaces and crosslinking molecules, the redox couples and counter electrodes used should also be considered carefully for higher photoconversion efficiency to ensure a smooth interfacial charge transfer at the photoanode/ electrolyte and electrolyte/counter electrode. Relative to the commonly used iodide/triiodide $\left(\mathrm{I}^{-} / \mathrm{I}_{3}{ }^{-}\right)$redox couple and platinum counter electrode in dye-sensitized solar cells (DSSCs), the sulphide/polysulphide redox couple and CuS counter electrode have been proposed to be suitable for metal chalcogenide (e.g., CdSe)-based QDSSCs, respectively. ${ }^{56,58,64}$ The presence of $\mathrm{Sn}^{2-}$ (oxidized counterpart) in the sulphide redox couple causes the quick scavenging of the photogenerated hole in the CdSe QDs by the redox couple, and thus regenerating QDs. However, the greater concentration of polysulfide also contributes the back electron transfer process. ${ }^{70}$ Leakage of the liquid electrolyte unfortunately results in a medium loss for charge transfer. Thus, solid-state electrolytes might be considered, such as polysulfide integrated polyvinylpyrrolidone. ${ }^{71}$ On the other hand, the penetration of solid electrolyte in the entire photoanode still is a challenging issue to be tackled. $\mathrm{ZnO}$ has also been applied for the counter electrode, in which the metal sulfide (e.g., CuS, PbS)-deposited $\mathrm{ZnO}$ nanorod counter electrode has shown better electrocatalytic activity than CuS (Table $2)^{72,73}$ The strategies to improve QDSSC performances by using $\mathrm{ZnO}$ nanostructured materials are summarized in Table 2. 
In addition to pursuing high photoconversion efficiency, the design of the assembly process (including materials used for sealing) is a limiting factor for long-term stability in a real application, even though it may not directly affect the performance. Extensive evaluation under various conditions, such as thermal, light and humidity stresses, should also be carried out to determining its stability. Afterward, the appropriate architecture and engineering of QDs-sensitized solar cells should be done comprehensively to make its practical application more feasible.

2.1.3 Perovskite-sensitized solar cells. Perovskite is a class of compound with the general formula $\mathrm{ABX}_{3}$, where $\mathrm{A}$ and $\mathrm{B}$ are cations with different sizes, and $\mathrm{X}$ is an anion. The first attempt that began the story of the perovskite-sensitized solar cells, or recently denoted as the perovskite-solar cell, (PSC) ${ }^{74-77}$ was made in 2009 by Kojima et al., where two organolead halide perovskite nanocrystals $\left(\mathrm{CH}_{3} \mathrm{NH}_{3} \mathrm{PbBr}_{3}\right.$ and $\left.\mathrm{CH}_{3} \mathrm{NH}_{3} \mathrm{PbI}_{3}\right)$ were found to efficiently sensitize $\mathrm{TiO}_{2}$ for visible-light conversion in photoelectrochemical cells. ${ }^{78}$ They reported that the solar energy conversion efficiency of $\mathrm{CH}_{3} \mathrm{NH}_{3} \mathrm{PbI}_{3}$, also known as methyl ammonium lead iodide (MAPI), is higher than $\mathrm{CH}_{3}$ $\mathrm{NH}_{3} \mathrm{PbBr}_{3}$ with a value of $3.8 \%$ and $3.1 \%$, respectively. After this breakthrough, many researchers focused on the development of MAPI-based PSCs. Their efficiency has significantly jumped from $3.8 \%$ to $20.7 \%$ in less than ten years. ${ }^{79}$

n-Type semiconductor oxides ( such as $\mathrm{TiO}_{2}, \mathrm{ZnO}$ ) are widely used as electron-transporting materials (ETMs) to extract and transport the photogenerated electrons. At the same time, they block the photogenerated hole to suppress charge recombination in perovskite bulk films. ${ }^{\mathbf{8 0}, 81}$ Considering their crucial role in the photovoltaic performance of PSCs, it is essential to control the characteristics of ZnO as the ETM layer, especially its morphology, interfacial properties, trap states, and energy level alignment. ${ }^{82}$

2.1.3.1 Influence of the ZnO nanostructure. Variations in the nanostructures have a significant impact on three aspects of the perovskite films: (i) the perovskite layer morphology and loading, (ii) the quality of the $\mathrm{ZnO} /$ perovskite interface, and (iii) the quality of the perovskite itself. ${ }^{81}$ In other words, $\mathrm{ZnO}$ with different nanostructures will lead to other PSC performances by affecting the perovskite directly, which will define the resulting PCE of a PSC. Briefly, the one-dimensional nanostructured ZnO (i.e., nanorods; NRs) showed better performances than $\mathrm{ZnO}$ nanoparticles (NPs). These results can be observed mainly due to the single crystal one-dimensional structures of $\mathrm{ZnO}$ provides direct electron pathways for the electronic transport in PSCs. ${ }^{\mathbf{8 0}}$ On the other hand, electrons suffer many trapping-detrapping events in NPs structures, especially at the grain boundaries that slow down the electron transfer. ${ }^{83-85}$ However, the trend cannot be linearly determined as there are other factors affecting PCE, besides the interacting properties of the perovskite and ETM in PSCs.

2.1.3.2 Influence of $\mathrm{ZnO}$ deposition and post-treatment method. Variations in the ZnO processing method may affect the interaction between the perovskite and ETM, which determines the overall PCE of the PSCs. Zheng et al. ${ }^{\mathbf{8 6}}$ showed that ZnO NPs deposited using the spin coating method resulted in a low power conversion efficiency (PCE) due to the formation of a pinhole-surface that creates the defective interface, leading to a loss of carriers. ${ }^{86}$ The PCE of the PSCs could be increased by adding the post-treatment method on the prepared ZnO NPs. Duan et al. showed that the addition of the in situ thermal decomposition on the spin-coated $\mathrm{ZnO}$ was able to change the morphologies of $\mathrm{ZnO}$ from nanoparticles to interconnect the net-like structure, leading to a power conversion efficiency increase to $13.1 \% .{ }^{87} \mathrm{~A}$ higher PCE could be acquired by using ZnO NR. Theoretically, NR can result in better PCE by providing a direct electron pathway with its one-dimensional structure. To improve the PCE even more, Mahmood et al. ${ }^{88}$ improved the conventionally low aspect-ratio (LAR) ZnO NR by directly introducing the PEI polymer as a capping agent during the hydrothermal growth process, which resulted in a high aspectratio (HAR) ZnO NR. This modification increases the PCE as NR with a large diameter, hindering the perovskite infiltrations in the ETM and resulting in an increase of PCE from $10.3 \%$ to $11.5 \%$. An even higher PCE can be achieved by passivating the

Table 2 Strategies to improve QDSSC performances

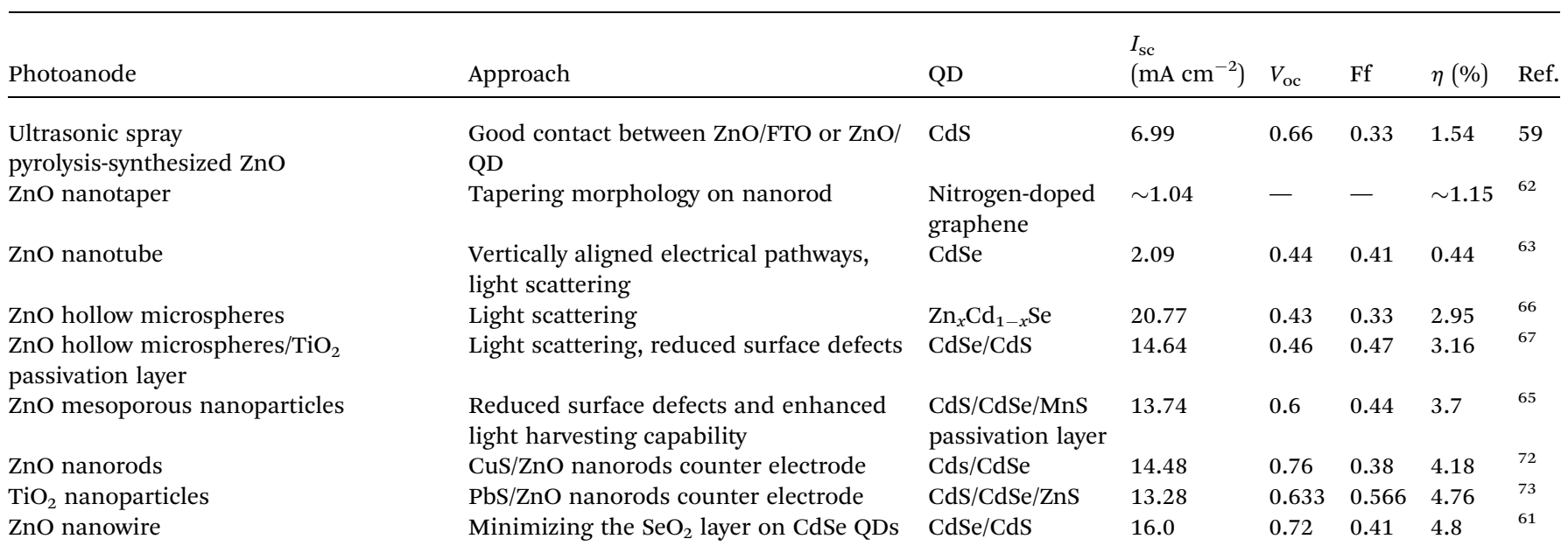


ZnO NR layer with $\mathrm{Al}_{2} \mathrm{O}_{3}$, along with the post-treatment of solvent-annealing in ethanol vapor. This particular method increases the carrier diffusion length, as well as the recombination resistance in PSCs, which can result in $17.3 \%$ efficiency. ${ }^{89}$

2.1.3.3 Influence of dopants and doping for interface engineering. More improvements of a PSC device can be achieved by improving the ZnO electronic properties for ETM by doping. Doping is already known to be adequate in modifying the electronic properties of metal oxide semiconductors. ${ }^{90}$ The doping can also significantly affect the morphology of $\mathrm{ZnO}$, and is usually used to increase the free charges and thus, conductivity in solar cells. ${ }^{\mathbf{8 1}}$ In the case of $\mathrm{ZnO}$, doping can be achieved by either replacing the $\mathrm{Zn}^{2+}$ cation or the $\mathrm{O}^{2-}$ anion. Cationic dopants are typically metals, whereas anionic dopants are nonmetals. Replacing $\mathrm{Zn}^{2+}$ by a different cation is expected to affect the conduction band (CB) structure. The upper edge of the valence band $(\mathrm{VB})$ consists of $\mathrm{O}^{2-} 2 \mathrm{p}$ bands and replacing $\mathrm{O}^{2-}$ with a different anion affects the VB energy. Therefore, the doping of $\mathrm{ZnO}$ can shift the Fermi level (EF) in the direction of the $\mathrm{CB}$, which helps increase the conductivity and facilitate the work function. ${ }^{\mathbf{8 1 , 9 1}}$

In the case of using $\mathrm{ZnO}$, several studies have shown the success in doping ZnO for PSC application. Dopants, such as $\mathrm{N}^{88} \mathrm{I}^{92} \mathrm{Al},{ }^{93} \mathrm{Ga},{ }^{94}$ and $\mathrm{Mg},{ }^{95}$ are the highly preferred n-type dopants for ZnO films. The work of Mahmood et al. ${ }^{88}$ achieved $16.1 \%$ PCE by altering the aspect-ratio of the $\mathrm{ZnO} \mathrm{NR}$, and also by doping $\mathrm{ZnO}$ with electron-rich nitrogen, which was proven to efficiently increase the conductivity of the oxide layer, reduce the internal resistance, and hence increase the electron density of the ETM. Zheng et al. reported iodine-doped $\mathrm{ZnO}$ as ETM. ${ }^{92}$ Through the treatment of introducing iodine, the usual hydrothermal process resulted in a wide-hexagonal-structure of ZnO:I nanopillars, making a compact and even planar ZnO:I thin film surface with few voids compared to ZnO NR arrays. Iodine-doping to $\mathrm{ZnO}$ also promotes an electron extraction from the perovskite layer by a more favourable work function of the ETM, leading to a PCE as high as $18.24 \%$ of the device. Al-doped ZnO (AZO) and Ga-doped ZnO (GZO) films are also excellent candidates for transparent conducting oxide materials because they are inexpensive, have suitable ionic radii, and show excellent optical transmission performance. The work of Mahmood et al. ${ }^{93}$ showed that Al doping could greatly enhance the carrier concentration and electron mobility of pure $\mathrm{ZnO}$, which results in superior conductivity. In addition to that information, Dong et $a l .{ }^{96}$ worked to improve ZnO NR by Al-doping, making AZO. The resulting Al-doped $\mathrm{ZnO}$ (AZO) is reported to have a higher conduction band, a higher electron mobility, and a higher electron density than ZnO. The study shows that the use of AZO resulted in an increase of the solar cell efficiency from $8.5 \%$ to $10.07 \%$, making them the first to fabricate the highly efficient Al-doped ZnO nanorod-based PSCs (Table 3). Summary of several factors that affect to photovoltaic performance of MAPI-based PSCs is presented in Table 3.

Table 3 The effect of $\mathrm{ZnO}$ nanostructure, preparation method, doping type, and other factors on photovoltaic performance of MAPI-based PSCs

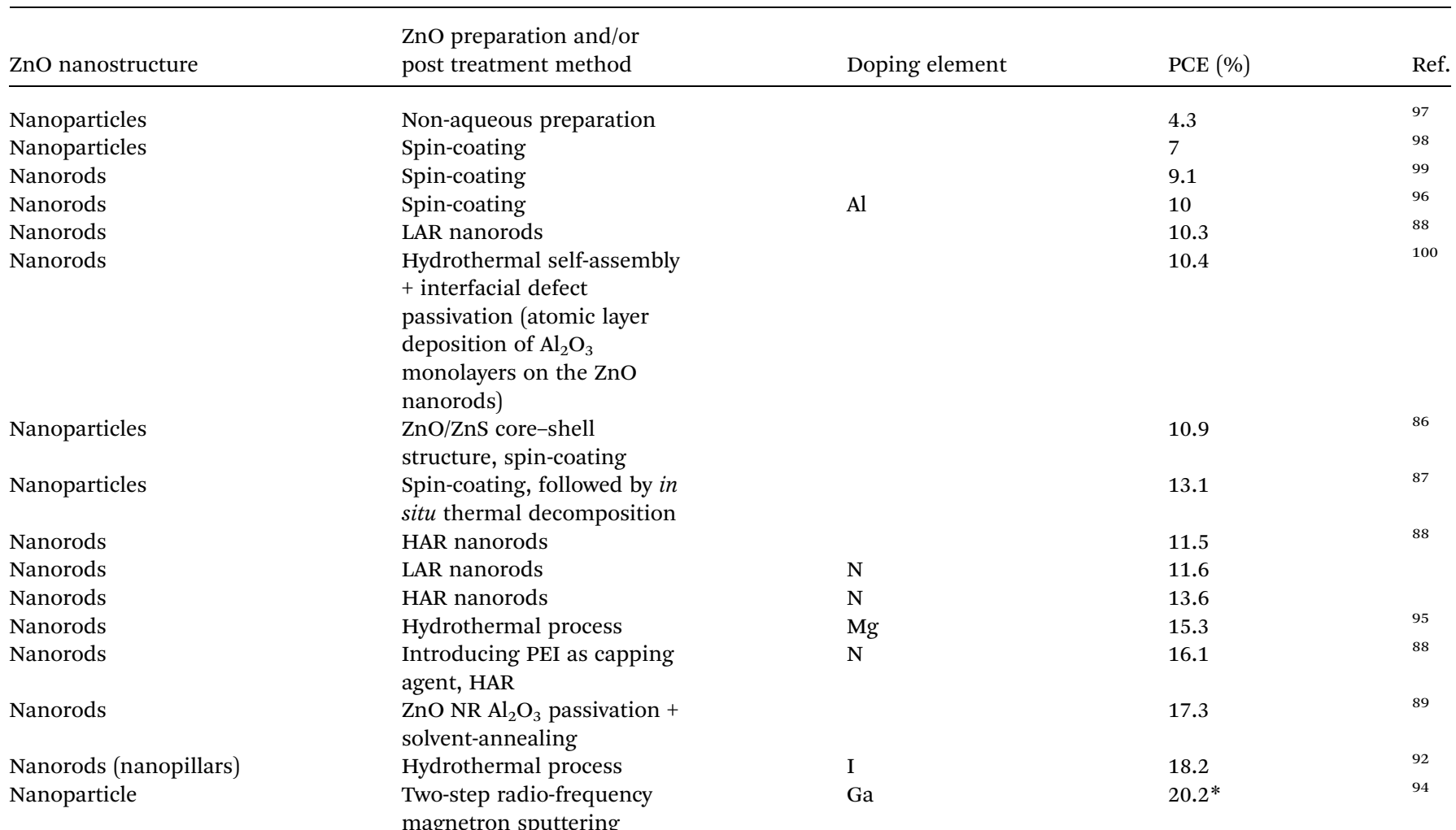


A study by Chen et al. ${ }^{94}$ showed that doping ZnO NR with Ga increased the carrier concentration such that an even higher power conversion efficiency of $20.167 \%$ was obtained, with an exciting transmittance value of $>87 \%$ in the range of $0.4-1.2 \mu \mathrm{m}$. Dong et al. ${ }^{95}$ also worked to make Mg-doped $\mathrm{ZnO}$, which is supposed to restrain the charge recombination in PSCs, owing to the conduction band offset at the $\mathrm{ZnO}$ /perovskite absorber interface, which increases the device efficiency.

Besides improving the $\mathrm{ZnO}$ properties, doping can also improve the PSC performance by simultaneously enhancing the interface interaction between the perovskite and the $\mathrm{ZnO}$, in other words: interface engineering. This is because the charge generation, separation, collection, and recombination mainly occur at the interfaces. Interface engineering would be necessary to lower the interfacial energy barriers for charge transport, to suppress charge recombination, and to improve the performance of the solar cell. ${ }^{15}$ For example, iodine-doping to $\mathrm{ZnO}$ resulted in a lower work function for efficient electron extraction from the perovskite into ZnO:I. This was achieved by reducing the photoluminescence decay life-time, which is favourable for inhibiting the charge recombination at the interface, leading to a remarkable enhancement of $J_{\mathrm{sc}}$ and FF, together with PCE. ${ }^{\mathbf{9}}$ Iodine-doping to $\mathrm{ZnO}$ also enables a better electrical contact interface between the perovskite and $\mathrm{ZnO}$ :I for facile charge transport, which effectively prevents charge accumulation at the interfaces. ${ }^{\mathbf{9 2}}$ The study made by Dong et al., ${ }^{\mathbf{1 0 1}}$ which improved $\mathrm{ZnO}$ to make AZO, was shown to improve the material as an ETM. It also indicates that the use of this compound could reduce the recombination at the $\mathrm{ZnO} \mathrm{NR} /$ perovskite interface. Ga-doped $\mathrm{ZnO}$ was also shown to have a crater-textured surface structure that can increase the contact area between ETM and perovskite, which reduces the contact resistance and increases the transmission channel of the electrons. ${ }^{94}$ The $\mathrm{Ga}$ doping in $\mathrm{ZnO}$ could increase the carrier concentration that makes the electrons effectively fill the interface traps and decrease the interface trap density, which was beneficial for reducing the electron capture and preventing carrier recombination at the interface, and improving the electron transporting efficiency from the perovskite to ETLs. Doping $\mathrm{Mg}$ to $\mathrm{ZnO}$ was also shown to raise the conduction band offset $(\Delta \mathrm{EC})$ at the $\mathrm{ZnO} /$ perovskite interface, suppressing the charge recombination, leading to improvements in cell performance. ${ }^{95}$

\subsection{Heterojunction solar cells}

2.2.1 Inorganic heterojunction solar cells. $\mathrm{ZnO}$ is widely being used in various forms of inorganic heterojunction solar cells, including quantum dot solar cells (QDSC), thin-film solar cells, and excitonic solar cells for multiple purposes (e.g., buffer layer, or as the n-type semiconductor in the active layer). One of the earliest examples of ZnO utilization in a fully inorganic solar cell was in 1976 by Kazmerski et al., utilizing the intrinsic ZnO layer and n-type $\mathrm{ZnO}: \mathrm{Al}$ in a $\mathrm{Cu}(\mathrm{InGa}) \mathrm{Se} 2$ :CDS thin-film solar cell. ${ }^{102}$ The intrinsic $\mathrm{ZnO}$ layer in this demonstration was used as a buffer layer between the active layer and cathode, and the $\mathrm{ZnO}: \mathrm{Al}$ blend functioned as a front contact. As time progressed, people started to utilize $\mathrm{ZnO}$ as an n-type semiconductor component for the $\mathrm{BHJ}$ active layer, owing to its high electron mobility, as well as the wide band-gap of $3.37 \mathrm{eV}$ at $300 \mathrm{K.}{ }^{\mathbf{1 0 3}}$

One of the most commonly found fully inorganic heterojunction solar cells consists of a mix between $\mathrm{ZnO}$ and lead chalcogenides (PbX; e.g., $\mathrm{PbS}$, PbSe, $\mathrm{PbTe}$ ). $\mathrm{PbX}$ has emerged as an excellent material for photovoltaic devices, as it has a uniquely large dielectric constant and therefore large Bohr radii, thus resulting in a significant quantum confinement effect. ${ }^{104}$ The energy level of $\mathrm{PbX}$ also favors combination with $\mathrm{ZnO}$, in which the LUMO of the PbX can be tuned to minimize the difference with the conduction band energy of $\mathrm{ZnO}$. Leschkies et al. reported a heterojunction solar cell based on the planar heterojunction between the PbSe nanocrystals and $\mathrm{ZnO}$ thin film. ${ }^{105}$ Compared to the Schottky solar cell made with similar PbSe NCs, the heterojunction solar cell utilizing the ZnO thin film features larger photocurrents and $V_{\text {oc }}$ value, with an overall power conversion efficiency (PCE) of 1.6\%. They found out that the thermal annealing of $\mathrm{ZnO}$ (up to $450{ }^{\circ} \mathrm{C}$ ) yields a positive effect on the electrical conductance and electron mobility of the ZnO film due to the reduced defects in the postannealed ZnO. To increase the efficiency, they proposed the utilization of nanostructures instead of planar films, like the one they used in this demonstration. Nanostructures provide a larger interfacial area for exciton dissociation compared to thin films. Thus, an increase in the overall device's performances were expected. Later, $\mathrm{ZnO}$ in the form of nanoparticles (ZnO NPs) was used as a substitute for $\mathrm{ZnO}$ thin film in a similar set-up; this time with $\mathrm{PbS}$ quantum dots nanocrystals as the $\mathrm{p}$ type material. ${ }^{106}$ Massive improvements can be seen in the PCE of the resulting cell, which almost doubles that of the planar ZnO cell $(\eta=2.94 \%)$.

Other than the lead-based p-type semiconductors, copper $\mathrm{p}$ type semiconductors were often used in combination with ntype $\mathrm{ZnO}$, including $\mathrm{Cu}_{2} \mathrm{O},{ }^{107} \mathrm{Cu}_{2} \mathrm{ZnSnS}_{4}$ (CZTS), ${ }^{108} \mathrm{Cu}$ (In,Ga) $\mathrm{Se}_{2}$ (CIGS), ${ }^{109}$ and several others. The copper-based solar cell shows high potential as a material for low cost and non-toxic solar cells, which is an advantage compared to the $\mathrm{Pb}$ or $\mathrm{Cd}$ based cells. ${ }^{110}$ In 2018, Zang et al. utilized a perfectly oriented, micrometer grain-sized $\mathrm{Cu}_{2} \mathrm{O} / \mathrm{ZnO}$ thin film to fabricate a solar cell with a PCE of $3.17 \% .^{110}$ The combination of the two yields outstanding results as the energy level favours each other for excitonic solar cell application; i.e., the conduction band minimum of $\mathrm{Cu}_{2} \mathrm{O}$ is slightly higher than $\mathrm{ZnO}$, and the valence band maximum of $\mathrm{ZnO}$ is lower than $\mathrm{Cu}_{2} \mathrm{O}$. However, up until now, the highest PCE from a combination of $\mathrm{Cu}_{2} \mathrm{O}$ and $\mathrm{ZnO}$ thin film is only around $3-4 \%$, which is still far lower than the theoretical PCE of $20 \% .{ }^{\mathbf{1 1 0 - 1 1 2}}$ In order to improve the efficiency, the interaction between $\mathrm{ZnO}$ and $\mathrm{Cu}_{2} \mathrm{O}$ (or other p-type semiconductor component for that matter) has a paramount importance to be addressed. Although nanoparticles (NPs) provide a large interfacial area, their uneven distribution may present a lack of facile electron pathway, causing high electron recombinant losses. Thus, new strategies must be developed, one of which includes the modification of the nanostructure's morphology.

Currently, most of the research is put into developing vertically-aligned nanostructures, such as nanorods or 
nanowires, as they offer the greatest interfacial area, as well as a facile pathway for charge transport. ${ }^{113}$ A demonstration in 2017 by Perng et al. reported the achievement of high to shortcircuit current density $\left(J_{\mathrm{sc}}=9.53 \mathrm{~mA} \mathrm{~cm}^{-2}\right)$ using chemical bath deposition of ZnO NRs, instead of the usual sputtering, in a $\mathrm{ZnO}$ NRs: $\mathrm{Cu}_{2} \mathrm{O}$ BHJ setup. ${ }^{114}$ The PCE was improved immensely when using the nanorods structure, reaching up to $0.861 \%$ compared to $0.107 \%$ of similar cells utilizing the $\mathrm{ZnO}$ thin film. ZnO nanowires (NWs):CdS was also introduced into the CIGS solar cell, with a consistent trend as the $\mathrm{Cu}_{2} \mathrm{O}$ solar cell (i.e., improved performances in cell employing NWs compared to thin-film). ${ }^{109}$ This work also demonstrates the possibility of performance enhancement effect using the piezo-phototronic effect; that is, increased performance with a suitable external mechanical strain. In the PbS QDs solar cell, ZnO NWs is also utilized, resulting in a cell with photocurrents of over $20 \mathrm{~mA}$ $\mathrm{cm}^{-2}$, and efficiencies of up to $4.3 \% .^{115}$ Later, Wang et al. reported the optimization of $\mathrm{ZnO} \mathrm{NWs} / \mathrm{PbS}$ QDs solar cells by tuning the PbS QDs dimension to study the performance of the device in the short-wave infrared region. ${ }^{\mathbf{1 1 6}}$ It turns out that the solar cell working in the short-wave infrared region exhibits high $V_{\text {oc }}$, making it a potential candidate for future uses as bottom or middle sub-cells in multijunction solar cells.

Recently, three-dimensional nanostructures in the form of a core/shell structure have been massively exploited. A 3D core/ shell structure with $\mathrm{ZnO}$ nanostructure as the core is another promising route for highly efficient solar cells due to its ability to allow decoupling of the electrical and optical properties, as well as enhanced light trapping in the solar cell structure. ${ }^{\mathbf{1 1 7}, \mathbf{1 1 8}}$ ZnO NWs and tin(II) sulfide (SnS) were combined to create a core/shell structure in a flexible solar cell using PET as the substrate, yielding a PCE of $1.2 \% .^{119}$ The piezo-phototronic effect was again taken as a strategy to enhance the performances in this flexible device, with a conversion efficiency increase of $37.3 \%$ under a moderate vertical pressure of 320 $\mathrm{KPa}$. Another demonstration of the core/shell nanostructure was demonstrated by Akram et al., this time with the $\mathrm{ZnO}$ blocking layer and CZTS as the p-type semiconductor. The Aldoped $\mathrm{ZnO} / \mathrm{ZnSe}$ core/shell nanorod arrays were grown from the $\mathrm{ZnO}$ seed layer, creating a solar cell with efficiency reaching $2.2 \%$, which is a massive improvement compared to a similar cell using the planar $\mathrm{ZnO}$ and $\mathrm{ZnS}$ as a buffer layer $(\eta=$ $0.16 \%) .{ }^{120}$ The core/shell structure with $\mathrm{ZnO} \mathrm{NWs} / \mathrm{AgGaSe}_{2}$ bulk heterojunction active layer was also fabricated. ${ }^{\mathbf{1 2 1}} \mathrm{AgGaSe}_{2}$, although not as relatively popular as other p-type semiconductors, offers a high absorption coefficient and convenient band-gap nature. It was discovered that the synthesis time has a direct effect on the core/shell structure diameter, i.e., an increase in diameter was observed with a longer growing time. A flexible solar cell on top of the PET substrate was successfully made with a PCE of $1.74 \%$. Careful optimization of the nanorod array's diameter, length and spacing must be done to increase the efficiency even further. ${ }^{120,122}$

The usage of the $\mathrm{ZnO}$ nanostructures in a fully inorganic solar cell is not limited to being a component in the active layer. $\mathrm{ZnO}$ nanorod arrays are used as an antireflection layer in CSZTSe and Si solar cells. ${ }^{\mathbf{1 2 3 , 1 2 4}} \mathrm{A}$ decrease in the average reflection from $7.76 \%$ to $2.97 \%$ was detected when switching from bare $\mathrm{ZnO}$ to $\mathrm{ZnO}$ NRs structure with $900 \mathrm{~nm}$ rod length in the CSZTSe solar cell. The trend shows better device performance as the nanorod synthesis time increases up to $9 \mathrm{~h}(\eta=$ $4.08 \%) .{ }^{123}$ It was hypothesized that the $\mathrm{ZnO}$ fill the voids and pores better as the synthesis time takes longer, resulting in more intimate interfacial conditions, thus creating a cell with better performance. The SEM image also shows that a longer synthesis time directly translates to longer nanorod length, which, in turn, is accompanied by decreased electrical resistance.

$\mathrm{ZnO}$ as a buffer layer was demonstrated in $\mathrm{a} \mathrm{Sb}_{2} \mathrm{Se}_{3}$ solar cell, replacing CdS as the conventionally used buffer layer due to its toxic nature. ${ }^{\mathbf{1 2 5}}$ The randomly oriented $\mathrm{ZnO}$ produced by spray pyrolysis induced a favourable crystal growth orientation of the $\mathrm{Sb}_{2} \mathrm{Se}_{3}$, resulting in a device with fewer interfacial defects and high efficiency of $5.93 \%$. Aside from better performance, the fabricated cell also offers superior stability, with only minor performance degradation after $1100 \mathrm{~h}$ of damp-heat testing (for comparison, a similar cell utilizing CdS dropped its efficiency from $5.67 \%$ to $5.16 \%$ after just $100 \mathrm{~h}$ of testing). Very recently in 2019, ZnO NPs were employed in a PbS colloidal quantum-dots (CQDs) system, with additional treatment in the form of oxygen annealing to the ZnO NPs to passivate its defects. ${ }^{\mathbf{1 2 6}}$ Oxygen annealing produced a cell with the highest performance, with an efficiency of $9.05 \%$ compared to $7.98 \%$ and $6.90 \%$ in ambient air and $\mathrm{N}_{2}$ atmosphere, respectively. This indicates that the introduction of $\mathrm{O}_{2}$ gas during annealing can reduce the surface defects originating from the oxygen vacancies in $\mathrm{ZnO}$ NPs.

Aside from the morphology adjustments, elemental doping and interfacial modification were also proven to be useful strategies for improving the device's performance. The localized surface plasmonic resonance (LSPR) is one of the strategies that is often implemented to increase the performance of a photovoltaic device. By modifying the size of a nanomaterial, it is possible to change and tune their band absorption. ${ }^{127}$ In 2015 , plasmonic Ag nanocubes were introduced to the PbS:ZnO NW solar cell for further improvement in its performances, particularly in the infrared and visible light region because of the plasmonic enhancement of light absorption in the range of 700-1200 nm. ${ }^{128}$ As a result, the PCE improved from $4.45 \%$ to $6.03 \%$ after the addition of $\mathrm{Ag}$ nanocubes at $25 \%$ coverage. An excess in the addition of $\mathrm{Ag}$ nanocubes, however, results in performance decline. This is due to the suppressed charge separation because of the hole-electron recombination at the surface of the nanocubes, and the possibility of $\mathrm{Ag}$ nanocubes aggregation. In its use as an electron extraction layer, the caesium-doped $\mathrm{ZnO}$ nanoparticles were synthesized and used in the PbS colloidal QDs system. ${ }^{129}$ Elemental doping in the form of caesium doping increases the cell efficiency by up to $10.43 \%$ with $5 \%$ doping of Cs, compared to $9.20 \%$ efficiency in the cell with pristine $\mathrm{ZnO}$ as the electron transport layer. The addition of $\mathrm{Mg}$ doping has been implemented to create a $\mathrm{Zn}_{0.9} \mathrm{Mg}_{0.1} \mathrm{O}$ layer using the sol-gel method. As an interlayer between $\mathrm{Sb}_{2} \mathrm{Se}_{3}$ and $\mathrm{ZnO}$, it was found to increase the PCE from $3.22 \%$ to $4.45 \%$, which was attributed to the interlayer's ability 


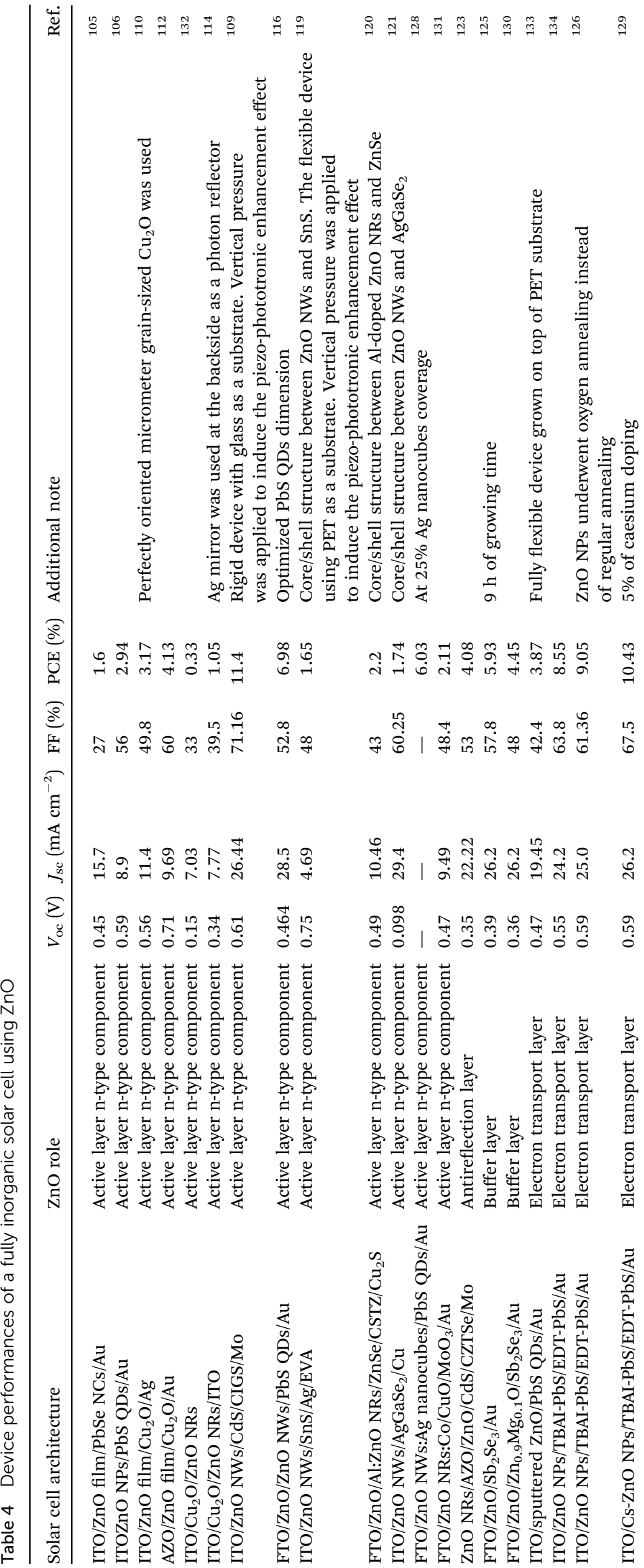


to passivate defects and reduce recombination losses. ${ }^{\mathbf{1 3 0}}$ Cobalt doping was used in a band-alignment approach to optimize the performance of the $\mathrm{CuO}$ nanostructure and $\mathrm{ZnO}$ NRs solar cell, using a low-temperature chemical bath deposition technique (Table 4). ${ }^{131}$ The device performances of a fully inorganic solar cell using $\mathrm{ZnO}$ are summarized in Table 4.

With $10 \%$ cobalt doping, a PCE of $2.11 \%$ was obtained due to the lowered band-gap of the ZnO layer.

Interfacial modification usually involves electrodeposition of another material to improve the interfacial condition. One of the most frequently used substrates for this purpose is carbonbased nanostructures, with graphene quantum dots gaining massive popularity due to its excellent luminescent property, good solubility, and pronounced quantum confinement effect. ${ }^{\mathbf{1 3 5}}$ Very recently, an example of interfacial modification was demonstrated using electrodeposited graphene-oxide onto a $\mathrm{ZnO}$ film, followed by thermal annealing to improve the relatively modest performance of the $\mathrm{ZnO} / \mathrm{Cu}_{2} \mathrm{O}$ heterojunction solar cells. ${ }^{107}$ Introduction of the graphene oxide nanosheets results in higher photo-electrical properties due to their strong interface properties. A decrease in the $\mathrm{ZnO}$ band-gap was also observed by the addition of reduced graphene oxide, which resulted in improved solar cell performance. ${ }^{\mathbf{1 3 6}}$ Chuang et al. managed to enhance the performance of ZnO NPs/PbS QDs cell through band alignment by utilizing various ligand treatments. ${ }^{134}$ They discovered that, by using tetrabutylammonium iodide (TBAI) and 1,2-ethanedithiol (EDT) as ligands for solidstate ligand exchange, a shift in the first exciton absorption peak to higher value was detected. Higher stability, $V_{\text {oc }}$, and $J_{\text {sc }}$ were observed after ligand addition. After layer stacking optimization between TBAI-PbS and EDT-PbS, a 35\% increase in PCE was detected compared to the cell using only TBAI-PbS.

\subsubsection{Hybrid organic/inorganic heterojunction solar cells}

2.2.2.1 ZnO as active layer in hybrid solar cells. Organicinorganic hybrid solar cells (HSCs) have been receiving significant attention due to its mechanical flexibility and potential to be made at a low cost. ${ }^{137}$ These hybrid solar cells combine two components to convert sunlight into electrical charge: (i) a conjugated polymer as an organic semiconductor, serving as a light harvester and electron donor, and (ii) an inorganic semiconductor acting as the electron acceptor. ${ }^{138} \mathrm{ZnO}$ has been widely used to replace the electron acceptor organic semiconductor present in fully organic solar cells (OSCs), mainly due to the observed higher electron mobility in the inorganic component of HSCs compared to most of the currently available n-type organic semiconductors, as well as higher physical and chemical stability. ${ }^{52}$ The overall energy production mechanism is very similar to that of OSCs, which involves exciton generation due to light illumination, which will then diffuse to the donor/acceptor interface within a certain diffusion length. The difference between the HOMO (highest occupied molecular orbital) and LUMO (lowest unoccupied molecular orbital) between the donor and acceptor material provides a driving force to overcome the binding energy of excitons generated in the previous step, dissociating them onto two separate free carriers by charge transfer. The positive and negative charges will then go to the cathode and anode, using continuous charge pathways provided by the acceptor and donor materials, respectively. ${ }^{139}$ Many nanostructures of $\mathrm{ZnO}$ have been investigated for HSCs applications, including nanoparticles, nanowires and nanorods. ${ }^{140-143}$ In this review, we will focus on discussing the three main device architectures of organicinorganic HSCs, which include: (i) bulk heterojunction HSCs with randomly dispersed nanocrystals, (ii) HSCs with vertically aligned nanostructures, and (iii) HSCs with organic-inorganic bilayer structure. ${ }^{\mathbf{1 4 4}}$

The utilization of $\mathrm{ZnO}$ in bulk heterojunction solar cells was first reported in 2004. Beek et al. managed to utilize separately prepared nanocrystalline $\mathrm{ZnO}$ (nc-ZnO) with a diameter of $\sim 5 \mathrm{~nm}$ via hydrolysis and condensation of zinc acetate dihydrate by $\mathrm{KOH}$ in methanol to create a bulk heterojunction HSCs, along with poly[2-methoxy-5-(3',7'-dimethyloctyloxy)-

1,4-phenylenevinylene] (MDMO-PPV) as the organic p-type semiconductor. This configuration managed to reach a power conversion efficiency (PCE) $\eta=1.6 \%$ at 0.71 sun equivalent intensity, and remained relatively stable at higher intensity of 1.7 sun equivalent $(\eta=1.4 \%) .{ }^{140}$ The forward current density observed in ZnO:MDMO-PPV was significantly higher than the one in pristine MDMO-PPV in a similar configuration, indicating that the presence of nc-ZnO does indeed provide a continuous pathway for electron transport. ${ }^{\mathbf{1 4 0}}$ The same group later tried to substitute MDMO-PPV to poly(3-hexylthiophene) (P3HT), due to it possessing higher hole mobility. ${ }^{145}$ However, the HSCs with P3HT shows a lower PCE of $0.9 \%$ when compared to the ncZnO:MDMO-PPV cell the group made earlier. ${ }^{\mathbf{1 4 0 , 1 4 5}}$ Previously, it was proposed that the main limiting factor of the organic-inorganic HSCs lies in the hole mobility of the organic phase. Thus, the lower result came as a surprise. ${ }^{146}$ It was later found that the presence of the hydrophilic pre-synthesized $\mathrm{ZnO}$ inside the polymer blend may negatively influence its ability to crystallize, thus reducing the hole mobility inside the polymer. An investigation using AFM shows that ZnO particles are not perfectly evenly distributed, especially at the interface with PEDOT/PSS, creating a thin layer consisting of pure polymer. This layer will hinder the excitons generated within the PEDOT/PSS to reach the $\mathrm{ZnO}$ interface to create a charge, reducing its internal quantum efficiency (IQE). ${ }^{\mathbf{1 4 7}}$ From these studies, it can be concluded that the lack of homogeneity in the particle dispersion caused by the nc-ZnO-based HSCs manufacturing process itself, as well as the lack of an intimate mixture between the organic and inorganic phase at the interface, contributes to an inefficient electron transport, reducing the device's overall efficiency. ${ }^{144,148}$

An alternative route of the $\mathrm{ZnO}$ HSCs fabrication can be done by utilizing $\mathrm{ZnO}$ in its precursor form, usually in the form of diethylzinc. ${ }^{\mathbf{1 4 9}}$ The precursor is first solved onto an organic solvent, and then cast into a thin film together with the polymer. When the mixture reacts with moisture in the air, the welldispersed $\mathrm{ZnO}$ particles are formed across the polymer film via hydrolysis reaction. ${ }^{\mathbf{1 5 0}}$ Thermal annealing near the polymer's glass transition temperature is usually employed afterwards to improve the polymer crystallinity, which will improve the hole mobility and packing. ${ }^{\mathbf{1 4 5}}$ This method was first demonstrated using $\mathrm{TiO}_{2}$ as the inorganic n-type semiconductor, but shows poor results due to the high temperature required to form 
crystalline $\mathrm{TiO}_{2}{ }^{149} \mathrm{ZnO}$, on the other hand, crystallized at a much lower temperature $\left(\sim 110^{\circ} \mathrm{C}\right)$. Using this precursorbased method, as well as the employment of the postfabrication thermal annealing, more evenly distributed $\mathrm{ZnO}$ nanoparticles across the film were observed. This enabled the previously modest performance nc-ZnO:P3HT cell to be improved immensely, increasing its PCE by $0.5 \%(\eta=1.4 \%) .{ }^{151}$ The three-dimensional morphology of $\mathrm{ZnO}$ was later employed with P3HT using the precursor method, yielding $\eta$ of $2 \%$ in the cell with $167 \mathrm{~nm}$ active layer thickness. This study highlights the effect of thickness on the cell's performance, in which thinner cells tend to exhibit lower properties. The relatively poor performance of the thin ZnO:P3HT HSCs was caused by the inefficient charge generation and charge transfer due to the coarse phase separation, thus presenting a lack of continuous pathway. $^{147}$

The usage of the $\mathrm{ZnO}$ nanocrystals was also demonstrated as an electron transport layer in a P3HT:PbS BHJ hybrid solar cell, with the CdSe quantum dot acting as a buffer layer. ${ }^{152}$ Here, the ZnO nanocrystals act as the electron transporting medium between the active layer and the ITO cathode, with the CdSe quantum dot layer bridging the energy difference between $\mathrm{ZnO}$ and the active layer due to its energy level lying in-between $\mathrm{ZnO}$ and P3HT:PbS. ZnO nanocrystals were synthesized separately and annealed at $230{ }^{\circ} \mathrm{C}$ for 20 minutes to promote crystallization. By tuning the size of the CdSe quantum dots, the best device of this approach managed to reach an efficiency of $2.4 \%$. The earlier demonstration had utilized the $\mathrm{ZnO}$ nanowire for the same purpose, displaying a fourfold photovoltaic performances compared to the device without a $\mathrm{ZnO}$ nanowire. ${ }^{\mathbf{1 4 2}}$

Besides the randomly dispersed nanoparticles, more 'controlled' and aligned nanostructures (such as nanorods and nanowires) are widely being developed. ${ }^{153}$ The vertically aligned nanostructures have been regarded as one promising candidate because the vertical alignment provides a higher interfacial area between the organic and inorganic material, creating a highly efficient pathway for the electron transport. ${ }^{154}$ One advantage of $\mathrm{ZnO}$ compared to other often utilized inorganic materials is the fact that the vertically aligned $\mathrm{ZnO}$ can be grown easily in many substrates via low-cost techniques, such as hydrothermal and solution methods. ${ }^{155-157}$ Olson et al. first demonstrated the idea of utilizing vertically aligned $\mathrm{ZnO}$ nanofibers in combination with P3HT to create an HSC device, in which the resulting device exhibited $\eta$ of $0.53 \% .^{158}$ The modest results are believed to be caused by several unoptimized parameters, such as the spacing between $\mathrm{ZnO}$ nanofibers $(100 \mathrm{~nm})$, which is too large when compared to the typical exciton diffusion length in P3HT (10-20 nm), resulting in an inefficient charge separation. ${ }^{\mathbf{1 4 8}}$ The same group later substituted the solvent used in P3HT solution from chloroform to dichlorobenzene. The device with dichlorobenzene shows a better result due to an improved polymer infiltration and polymer chain ordering. ${ }^{159}$

Much like the nanoparticle structures, annealing near the polymer's melting temperature for a short time provides more time for the polymer to arrange between the nanofibers. This provides a better, more intimate interface between the two phases, therefore reducing the geminate recombination. ${ }^{160}$ An increase in the polymer crystallinity was also observed. By such optimization, as well as the optimization of the $\mathrm{ZnO}$ backing layer thickness, Baeten et al. managed to report a noticeable increase in the device performance of the $\mathrm{ZnO}$ nanorod arrays coupled with P3HT. ${ }^{160}$ It is important to note that the best device produced by thermal annealing only underwent this process for $1 \mathrm{~min}$ at $225^{\circ} \mathrm{C}$, as further annealing (up to $15 \mathrm{~min}$ ) showed diminishing performance due to unfavourable polymer chain ordering. ${ }^{160}$ An optimized performance of PCE $1.44 \%$ was later demonstrated in an inverted cell structure with $0.08 \mathrm{~mol} \mathrm{~L}^{-1}$ concentration of the precursor, $5 \mathrm{~h}$ of the hydrothermal time, followed by $100{ }^{\circ} \mathrm{C}$ thermal annealing, and spincoating 3 layers of PEDOT:PSS. ${ }^{156}$ Surface engineering of the $\mathrm{ZnO}$ nanostructures may also be employed to further increase its performance (Table 5). Device performances of organicinorganic hybrid solar cells using $\mathrm{ZnO}$ as active layer component are summarized in Table 5.

In 2017, Dkhil et al. incorporated a p-type semiconductor ligand ((E)-2-cyano-3-(5'-(4-(dibutylamino)styryl)-2,2'-bithiophen5 -yl)acrylic acid), grafted as the interfacial surfactant on $\mathrm{ZnO}$ nanorods, to improve the interfacial bonding between the two phases in the ZnO-NR:P3HT cell. ${ }^{162}$ The best device produced by this approach yields a PCE of $0.93 \%$, which is better than the ZnO-NR:P3HT cell without any surfactant modification. To further improve the performance, the development of a suitable n-type semiconductor ligand was proposed by the same group to enhance the compatibility between the organic-inorganic phases. ${ }^{162}$ It should be noted that the ligand-related approaches can also be applied with other $\mathrm{ZnO}$ /polymer HSCs architectures, and has been demonstrated in both dispersed nanoparticles and vertically aligned nanostructures alike. ${ }^{\mathbf{1 6 2 , 1 6 7}}$ Chemical etching with protonic and anionic agents were also demonstrated, and showed positive results owing to the favourable $\mathrm{ZnO}$ nanorod morphology. The $\mathrm{KOH}$-treated $\mathrm{ZnO}$ nanorods showed the most significant improvement due to the defect quenching phenomenon provided by $\mathrm{KOH} .{ }^{163}$ The unique surface structure in the form of the trilaminar $\mathrm{ZnO} / \mathrm{ZnS} / \mathrm{Sb}_{2} \mathrm{Se}_{3}$ nanotube (NTs) arrays was used in conjunction with P3HT, where $\mathrm{ZnO}$ was used as a buffer layer and $\mathrm{Sb}_{2} \mathrm{Se}_{3}$ as sensitizer. ${ }^{164}$ The structure was reported to be able to suppress carrier recombination and increase electron collection efficiency due to better energy level alignment of the trilaminar structure with $\mathrm{P} 3 \mathrm{HT}$, thus giving a rise in PCE of $1.32 \%$.

The bilayer structure is another important and widely studied architecture of organic-inorganic HSCs. This architecture first deposits a $\mathrm{ZnO}$ layer above the electrode surface, followed by the deposition of the p-type organic semiconductor, and topped by the top electrode. Unsurprisingly, this simple architecture usually yields lower performance than two previously discussed architecture (e.g., dispersed nanoparticles and vertically aligned nanostructures), mainly due to the smaller interface area available for electron transport. ${ }^{168}$ Regardless, various efforts have been made to improve the properties of such a simple structure, which includes doping and surface modification. ${ }^{\mathbf{1 6 5 , 1 6 8 , 1 6 9}}$ Olson et al. first reported the effect of interfacial modification on polymer/ZnO bilayer devices in 2008. The demonstration shows that the $\mathrm{ZnO} / \mathrm{P} 3 \mathrm{HT}$ device, 
which undergoes heating at $150{ }^{\circ} \mathrm{C}$ exhibits much higher $V_{\mathrm{oc}}$ (difference of around $200 \mathrm{mV}$ ) compared to the device treated with ozone/UV, owing to changes in the interfacial dipoles, causing a band alignment shift at the interface. ${ }^{165}$ The efficiency rises from $0.02 \%$ to $0.07 \%$ when switching from ozone/UV treatment to heating, although their performance is still lower than similarly treated $\mathrm{ZnO}$ nanorods-based devices. ${ }^{\mathbf{1 5 8 , 1 7 0}}$ Chemical doping of $\mathrm{ZnO}$ with other elements, such as $\mathrm{Mg}$, has also been successfully demonstrated and yields favorable results. ${ }^{166}$

2.2.2.2 ZnO as the cathode buffer layer in organic solar cell. In addition to being an electron acceptor in HSCs, ZnO is also often used in fully organic solar cells (OSCs) as the cathode buffer layer (CBL). Similar to HSCs, the conjugated polymer takes the role of being the p-type semiconductor. However, instead of utilizing the inorganic component, fullerenederivatives (e.g., PCBM) are used as the electron acceptor and electron transporting material. ${ }^{171}$ It has been known that OSCs, especially the conventional type, exhibit low stability due to the susceptibility of its metal cathode (e.g., Al) used in OSCs to moisture and air. The insertion of $\mathrm{ZnO}$ materials into the interface between the active layer and cathode as a buffer layer has been demonstrated in many cases. The approach shows an overall positive result in improving the stability of the cell. On the other hand, the favourable energy band of $\mathrm{ZnO}$ also makes it very suitable for this purpose, as the lowest conduction band energy of $\mathrm{ZnO}$ is lower than the LUMO of typical fullerene- derivative semiconductors. The highest valence band energy of $\mathrm{ZnO}$ is lower than the HOMO of polymer donor semiconductors, such as P3HT. ${ }^{\mathbf{1 7 2 , 1 7 3}}$ This essentially means that $\mathrm{ZnO}$ can both help to extract and collect electrons in the fullerene acceptor, while also blocking the unwanted reverse flow of the hole from the polymer donor into the cathode, preventing the generation of a leakage current. Usage of $\mathrm{ZnO}$ was demonstrated in both conventional and inverted solar cell structures, and the two will be discussed in this review.

In 2011, Jouane et al. demonstrated the introduction of a ZnO layer onto the active layer of a P3HT:PCBM conventional organic solar cell via rf magnetic sputtering. The deposition of the $\mathrm{ZnO}$ layer causes no functional damage to the photoactive layer, and increases the cell efficiency from $2.16 \%$ to $2.34 \%{ }^{174}$ Interface engineering between the backing layer and metal cathode is also needed to improve the device performance in both OSCs and HSCs. The self-assembled monolayer (SAM) has been implemented in photovoltaic device fabrication to tune the characteristics of the $\mathrm{ZnO}$ surface. ${ }^{\mathbf{1 7 5}}$ Modification of the $\mathrm{ZnO}$ surface in the CBL/cathode interface with the carboxylic acid-based SAM has been demonstrated using various different metals as the cathode. ${ }^{176-178}$ They found out that the dipole direction and chemical bonding between the $\mathrm{CBL} /$ cathode are two key factors in improving the device performance, in which the favorable dipole generated ohmic contacts and will improve the device efficiency.

Where ZnO-based CBL truly found its uses, however, is in the inverted structure of the OSCs. The inverted structure

Table 5 Device performances of organic-inorganic hybrid solar cells using $\mathrm{ZnO}$ as active layer component

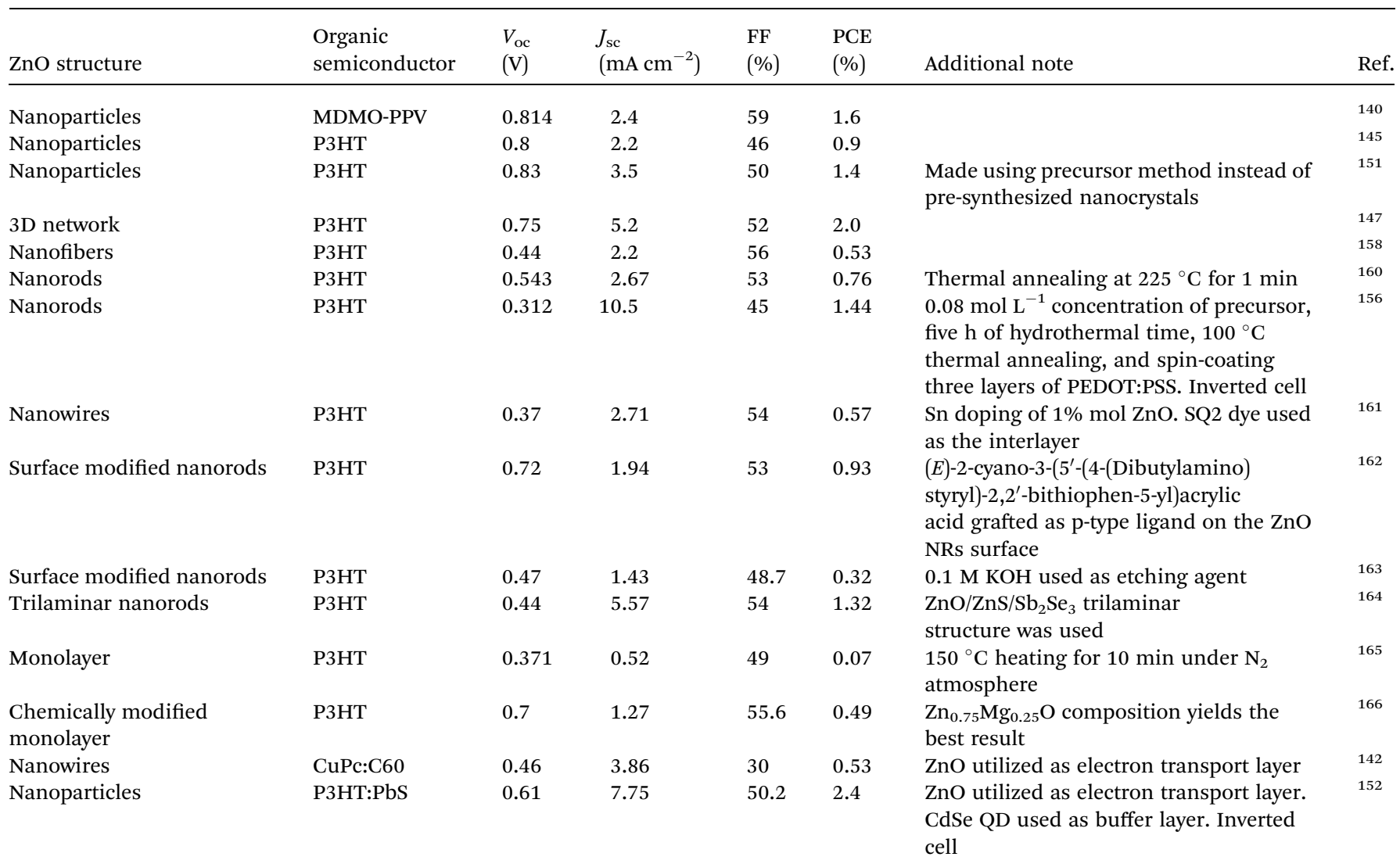


eliminates the mandatory need of the PEDOT:PSS layer, which may cause etching on the ITO glass, resulting in a degradation of the cell. ${ }^{179}$ The inverted structure also enables a low-workfunction metal (like $\mathrm{Al}$ ) to be replaced by an air-stable high-workfunction metal, such as $\mathrm{Ag}$ or $\mathrm{Au}$, resulting in much greater stability. Earlier fabrications of inverted OSCs generally reported lower PCE than conventional cells, but recent studies have shown that it is possible to fabricate high performance and high stability inverted cells. ${ }^{180}$ However, when using P3HT:PCBM based OSCs, the reported PCEs are mostly less than $5 \%$.

To combat this, a new fullerene derivative with higher LUMO is being developed to increase the overall $V_{\mathrm{oc}}$ and therefore device efficiency. An example of the recently developed fullerene derivative is the indene- $\mathrm{C}_{60}$ bisadduct (ICBA), which has a LUMO of $-3.74 \mathrm{eV}$ compared to $-3.91 \mathrm{eV}$ of PCBM. ${ }^{181} \mathrm{~A}$ blend of ICBA and P3HT has been implemented in conventional solar cells and yielded an impressive PCE of $5.44 \%$, which is superior to that of the P3HT:PCBM device with PCE of $3.88 \%{ }^{182}$ When used in the inverted solar cell, a $V_{\text {oc }}$ of $0.82 \mathrm{~V}$ was achieved, which is higher than the $V_{\text {oc }}$ limitation of the P3HT:PCBM blend of $0.65 \mathrm{~V} .{ }^{181}$ Fabrication of a similar inverted cell using inkjet printing instead of the spin coating was demonstrated by Ganesan et al. in 2019. However, the fabricated cell performance still falls short $(\eta=4.7 \%)$ due to the unoptimized printing parameters. ${ }^{183}$ Using the same logical approach, the [6'6]-phenyl $\mathrm{C}_{70}$-butyric acid methyl ester $\left(\mathrm{PC}_{70} \mathrm{BM}\right)$ was blended with poly $\left[5,5^{\prime}\left(4,4^{\prime}\right.\right.$-bis-(2-ethylhexyl)-dithieno[3,2- $b: 2^{\prime}, 3^{\prime}$ - $\left.d\right]$ germole)-alt-1,3(5-octyl-4H-thieno[3,4-c]pyrrole-4,6(5H)-dione)] (P$\mathrm{Ge})$ to form an active $\mathrm{BHJ}$ layer in the inverted solar cell, in which the resulting solar cell exhibited a PCE of $7.3 \%$, without compromising its stability. ${ }^{\mathbf{1 8 4}}$

Various nanostructure parameters of $\mathrm{ZnO}$, such as the size and surface area, also play an integral part in determining the overall device performance. ${ }^{\mathbf{1 8 5}}$ There have been many demonstrations of low-dimensional $\mathrm{ZnO}$ nanostructures utilized in OSCs, both in the form of simple nanoparticles and onedimensional nanostructures. Hau et al. reported the utilization of $\mathrm{ZnO}$ nanoparticles in the inverted OSCs structure, with the P3HT:PCBM active layer and PEDOT:PSS/Ag as an anode. The resulting device with the nanoparticle arrangement of $\mathrm{ZnO}$ exhibited higher efficiency compared to $\mathrm{ZnO}$ deposited using the sol-gel method in a similar cell setup. ${ }^{176}$ It should also be noted that the ZnO NP is synthesized at room temperature with a solution method, compared to the bulk $\mathrm{ZnO}$ processed with high temperature sol-gel method. However, a similar problem with the NP-based HSCs arises, in which the randomly dispersed nanoparticles do not provide an adequate pathway for charge transport, which may limit the device efficiency due to a higher rate of electron recombination losses compared to aligned, one-dimensional nanostructures. ${ }^{\mathbf{1 1 3}}$ Recently, annealing-free $\mathrm{ZnO}$ nanoparticles were fabricated by Jung et al. in 2018. ${ }^{155}$ This demonstration not only yields a respectable PCE of $7.41 \%$, but more importantly, also demonstrated the possibility of skipping the annealing process, which may damage the substrate and active component during the fabrication.

One-dimensional nanostructures have been regarded as a promising approach to fabricate efficient OSCs. Such 1D structure can provide a direct and ordered pathway from the photogeneration site into the metal cathode, reducing the electron recombination losses, thus increasing the overall device performance. ${ }^{113}$ Takanezawa et al. demonstrated the usage of the $\mathrm{ZnO}$ nanorods array with controlled dimension, and coupling the nanorods with the P3HT/PCBM polymer blend to produce OSCs with PCE of up to $2.7 \% .{ }^{186}$ This experiment uses the spin-coating method to reliably control the organic layer thickness, as well as the post-fabrication thermal annealing process. Nanorods in this experiment were made via the hydrothermal method, yielding a nanorods array with a diameter of $20-40 \mathrm{~nm}$ and length of $\sim 0.3 \mu \mathrm{m}$. From this work, it was concluded that the nanorod's length and the organic layer's thickness play an important role in determining the device's efficiency, in which performances were found to improve with the increase of the average NR length. ${ }^{\mathbf{1 8 6}}$ Chou et al. reported in 2009 that the slow-drying process, which lengthens the polymer's solidification time, can improve the FF and PCE of the inverted ZnO:P3HT/PCBM $(\eta=3.58 \%)$ due to the improved polymer crystallinity and infiltration of the photo-active layer. ${ }^{187}$

Nevertheless, compared to $1 \mathrm{D}$ structures, the nanoparticle structure provides better electron collection from the photoactive layer compared to the $1 \mathrm{D}$ nanostructure. Thus, the combination of the two, forming a bilayer of ZnO NR-ZnO sol gel was demonstrated in 2015 by Ambade et al., in which the fabricated P3HT:PCBM cell exhibited a PCE of $3.70 \% .{ }^{188}$ This novelty was explored to demonstrate the possibility of such efficient bifunctional CBL, in which the sol-gel layer first efficiently collects the electron, and is then transported effectively by the nanorods into the cathode. Another novel 1D nanostructure of $\mathrm{ZnO}$ that exhibited similar nanostructure to that of the previously mentioned bilayer CBL was also explored. Sekine et al. synthesized $\mathrm{ZnO}$ nanoridges in a thin film with a peak height of $\sim 120 \mathrm{~nm}$ and distance between 'valleys' of around $500 \mathrm{~nm}$. The synthesis of the $\mathrm{ZnO}$ nanoridges was done using a sol gel method similar to that of the planar $\mathrm{ZnO}$ synthesis, but different annealing conditions. ${ }^{189}$ The presence of the $\mathrm{ZnO}$ nanoridges structure shows a significant performance improvement compared to that of the planar $\mathrm{ZnO}$, with the P3HT:PCBM ZnO nanoridge inverted solar cell reaching an efficiency of $4 \%$. More recently in 2017, Ryu et al. demonstrated the utilization of $\mathrm{ZnO}$ nanoridges with a low static annealing temperature of $150{ }^{\circ} \mathrm{C}$, which makes the temperature low enough for co-processing plastic substrates for flexible device applications. ${ }^{190}$ A PCE of $6.24 \%$ was obtained using said $\mathrm{ZnO}$ combined with a PTB7-F20:PCBM active layer.

Aside from altering the nanomorphology of the CBL, better performance can be achieved by modification of the $\mathrm{ZnO}$ itself, which may include surface modification or elemental doping. Surface modification ranges from the introduction of dyes, ${ }^{191}$ SAMs (self-assembled monolayers), ${ }^{192}$ and fullerene-derivatives. ${ }^{193}$ The addition of $\mathrm{C}_{60}$-SAMs has been reported to enhance the device performance by up to $20 \%$ increase, owing to the enhanced interfacial exciton dissociation energy. ${ }^{\mathbf{1 9 4}}$ Another fullerene-derived organic molecule, crosslinked-[6,6]-phenyl$\mathrm{C}_{61}$-butyric styryl dendron ester (C-PCBSD) was used to modify the surface of $\mathrm{ZnO}$, yielding a PCE of $4.4 \%$ when incorporated 


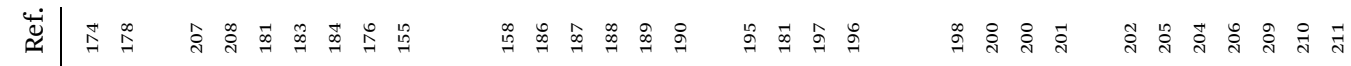

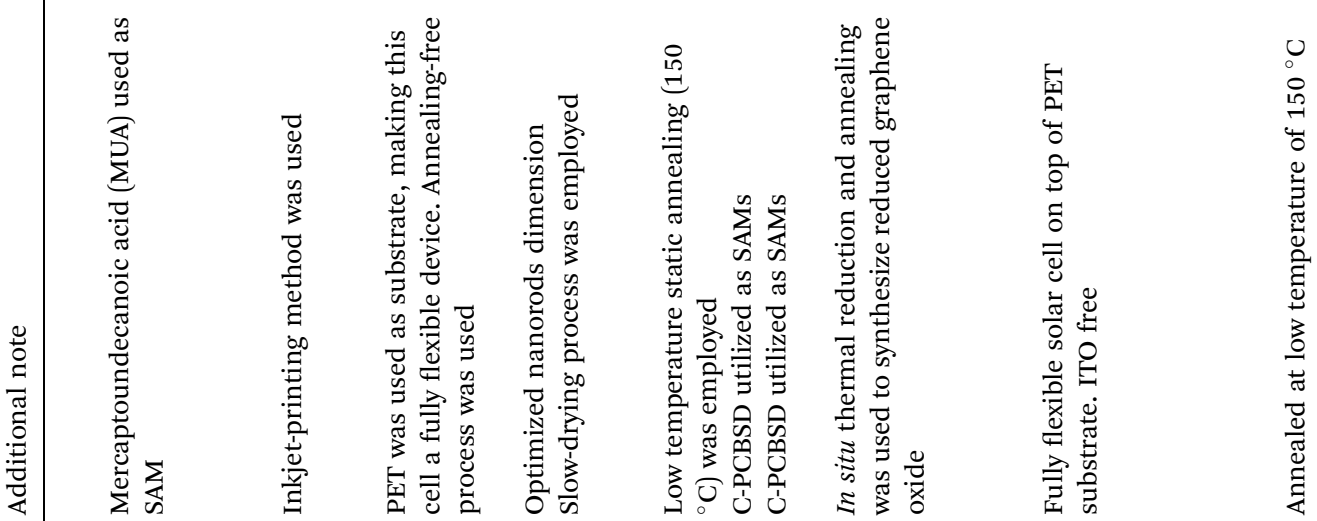

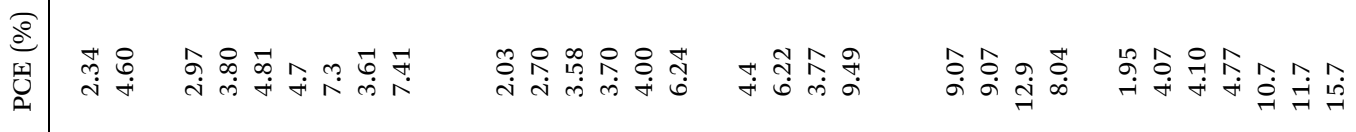

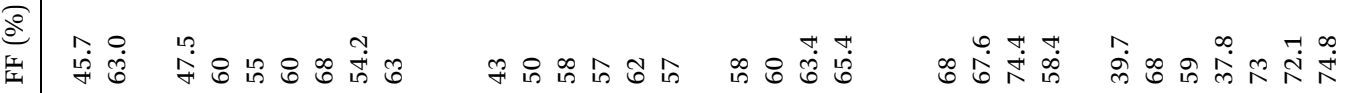

:

造

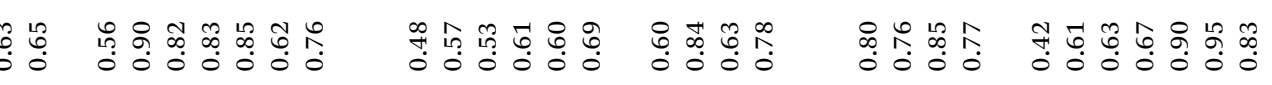

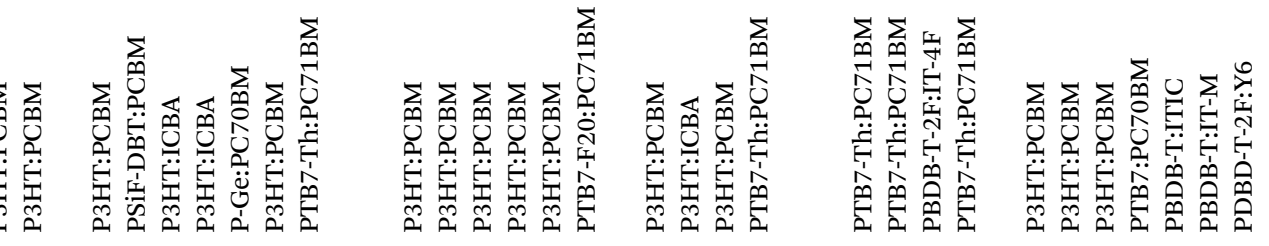

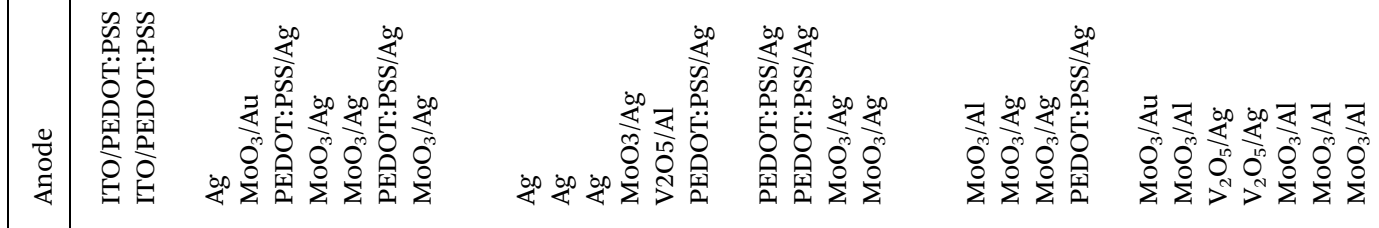

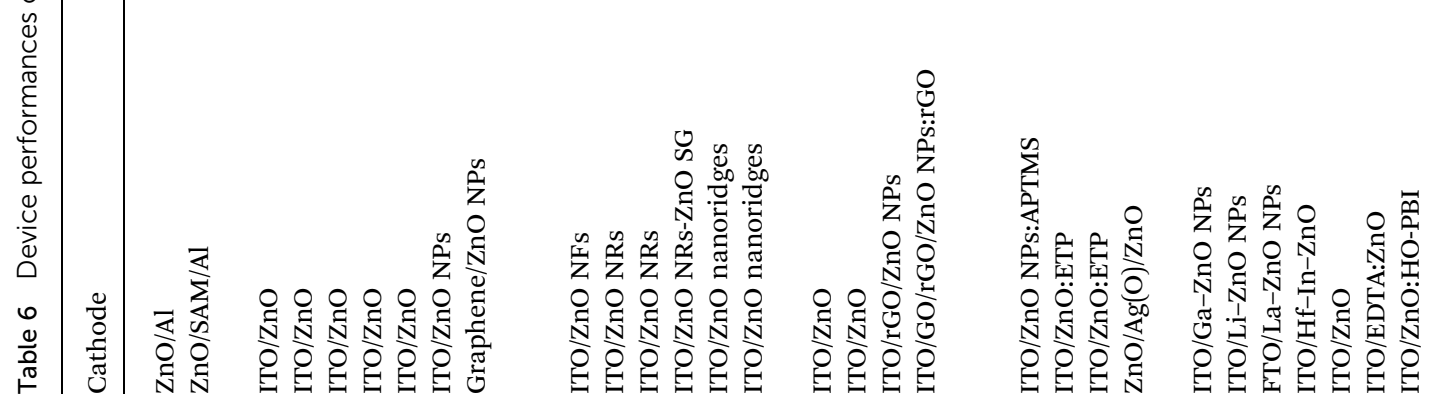


into the P3HT:PCBM OSC, ${ }^{195}$ and $6.22 \%$ in the P3HT:ICBA OSC, ${ }^{\mathbf{1 8 1}}$ as well as a significantly improved lifetime in both compared to cells without surface modification. ${ }^{182}$ Surface modification with graphene oxide and reduced graphene oxide has also been demonstrated, yielding an inverted cell with PCE as high as $9.49 \%$ in the cell utilizing in situ thermal reduced graphene oxide. ${ }^{196,197}$ Silane has also been used as a capping agent for ZnO NPs to prevent aggregation. This is an attempt to improve the solar cell's stability, and the quality of the interfacial contact between the active and the buffer layers. Wei et al. demonstrated the synthesis of the 3aminorpropyltriethoxysilane-capped $\mathrm{ZnO}$ nanoparticles, which can remain stable in air for more than one year. ${ }^{198}$ Recently, the down-shifting effect has been proven to be able to increase the solar cell performance by converting UV light to visible light. ${ }^{199}$ Lanthanide down-conversion material, with the ability to absorb UV light and re-emit it in the visible region, was added to the $\mathrm{ZnO}$ electron transport layer, so that the re-emitted light matches the absorption energy level of the active layer material. $^{200}$ Here, Eu(TTA) ${ }_{3}$ phen (ETP) was used as the downconversion material, with PTB7-Th: $\mathrm{PC}_{71} \mathrm{BM}$ as the active layer, resulting in a cell with PCE of $9.22 \%$ and $70 \%$ higher stability compared to the cell with pristine ZnO. In 2020, Shen et al. demonstrated the fabrication of ITO-less solar cells, using oxygen-doped $\mathrm{Ag}$ and plasmonic $\mathrm{Ag} @ \mathrm{SiO}_{2}$ as a countermeasure for the lack of the ITO layer, taking advantage of both microresonant cavity and plasmonic effect. ${ }^{201}$ The optimized cell displays a PCE of $8.04 \%$, which is $36.27 \%$ higher than the ITObased cell.

Elemental doping with elements, such as La, In and Ga, has been reported to dramatically increase the efficiency of organic solar cells, with Ga-doped ZnO (GZO) reportedly increasing the cell PCE by $110 \%$, owing to the higher electron conductivity and better wettability due to the favourable surface morphology. ${ }^{\text {202-204 }}$ More recently in 2016, Li-doped ZnO has been utilized as CBL in the P3HT:PCBM cell, and managed to obtain $30 \%$ improvement from the non-doped ZnO CBL layer due to the enhanced electron mobility, smoother surface morphology and better energy band matching in the Li-ZnO CBL. ${ }^{205}$ This approach has also been demonstrated in the nonP3HT:PCBM cell. For example, in 2018, Hf-In-ZnO was used as an electron transport layer in the inverted PTB7:PC ${ }_{70} \mathrm{BM}$ solar cell, yielding a solar cell with an efficiency of up to $4.15 \%$, with twice the lifetime of a similar OSC with PFN as a buffer layer, because the Hf atoms have a strong thermodynamic tendency to form metal oxides, suppressing the dissociation of $\mathrm{Hf}-\mathrm{In}-\mathrm{ZnO}$ (Table 6). ${ }^{206}$ Summary of device performances of organic solar cells using $\mathrm{ZnO}$ as cathode buffer layer is shown in Table 6.

Very recently, however, it has been known that the fullerenebased OSCs' performances are being limited by its poor light absorption, as well as instability in morphology. ${ }^{212}$ Huge efforts are made to substitute PCBM and the other fullerene-derived acceptor with a non-fullerene one. Zhao et al. demonstrated the usage of ITIC, a non-fullerene n-type acceptor, coupled with PBDB-T to create an active layer, with $\mathrm{ZnO}$ as a buffer layer. $\mathrm{ZnO}$ in this demonstration was synthesized via precursor solution method, and the resulting inverted cell exhibited a PCE of $10.71 \%$, as well as excellent stability of $83 \%$ retained PCE after over $4000 \mathrm{~h} .{ }^{209}$ However, further annealing at high temperature was needed to reduce the defects, which is energy consuming and not desirable, especially when working with a polymeric substrate. Later in 2017, Li et al. incorporated ethylene diamine tetraacetic acid (EDTA) with the ZnO precursor to passivize the defects in $\mathrm{ZnO}$ due to its chelation function, effectively lowering the required annealing temperature. On the other hand, the low conductivity of EDTA can be mitigated by ZnO's high conductivity. The combination of the two, in conjunction with PBDBT:IT-M BHJ active layer solar cell, displays a PCE of $11.67 \%$, and a FF of $72.1 \% .^{210}$ The previously mentioned solar cell employing ETP as down-conversion material was also tested using this approach, replacing the PTB7-Th:PC71BM with PBDB-T-2F:IT-4F, increasing its efficiency from $9.22 \%$ to $13.12 \% .{ }^{200}$ Another non-fullerene active layer, PDBD-T-2F:Y6, has been utilized as a $\mathrm{BHJ}$ active layer, with the $\mathrm{ZnO}$ thin film as the buffer layer. This time, however, the ligand was also used in the form of tetrahydroxy-perylene bismide (HO-PBI ligand),

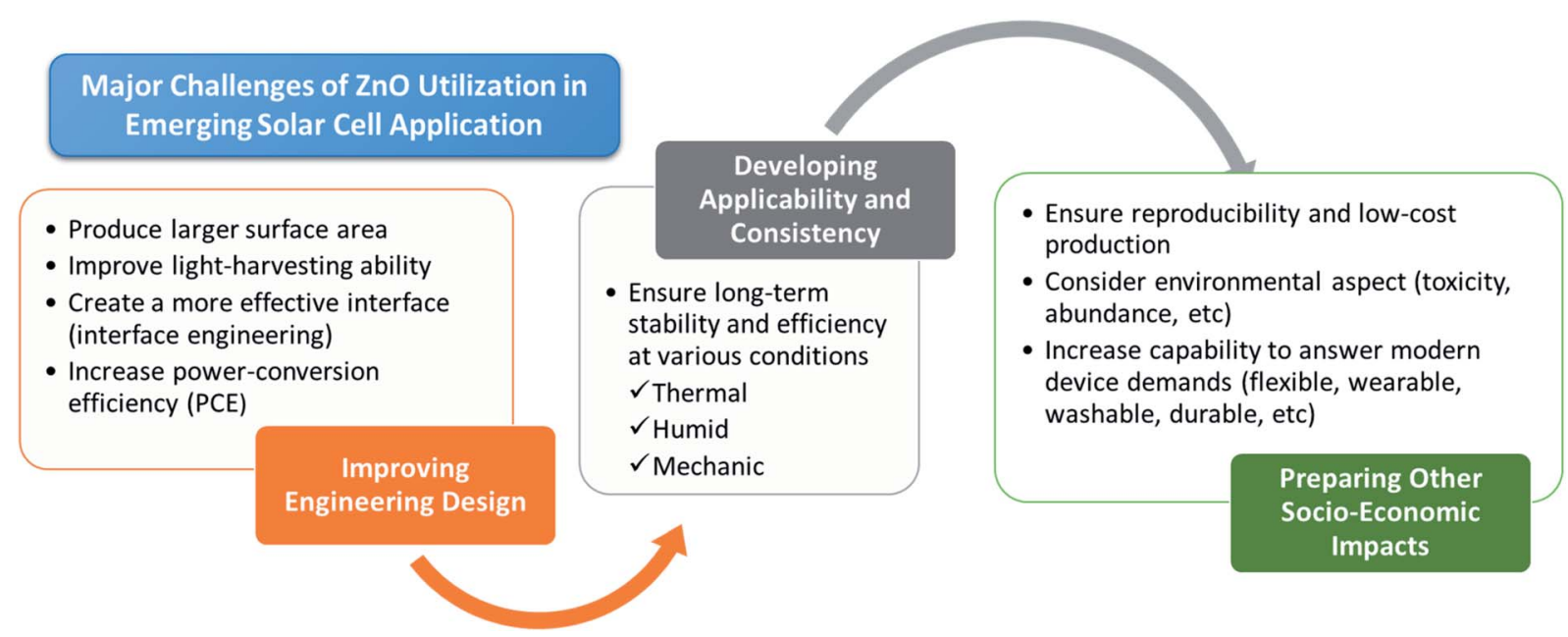

Fig. 3 Major challenges for $\mathrm{ZnO}$ solar cell development. 
embedded onto a $\mathrm{ZnO}$ thin film, improving the device efficiency up to $15.73 \%$, making it one of the highest reported nonfullerene based OSCs to date. ${ }^{211}$ The high efficiency is attributed to the higher solubility and better molecular dispersion of ZnO:HO-PBI, resulting in the robust coordination between organic molecules and the metal oxide lattice, leading to increased electron mobility and easier electron transport.

\section{Summary and future outlook}

In this review, the application of $\mathrm{ZnO}$ as an active material in emerging solar cells technologies, including dye-sensitized solar cell (DSSC), QDSC (ouantum-dots sensitized solar cell), PSC (perovskite-sensitized solar cell), inorganic solar cell, Organic Solar Cell (OSC), Hybrid Solar Cell (HSC) is discussed. The inorganic solar cell is one of the earliest generations of solar cells, and is more mature than polymeric-based devices. Various combinations of metals, alloys and oxides, as well as unique nanostructures, fabrication methods, elemental doping and interfacial modifications, have been studied to increase the cell performances and stability. However, the issues regarding the abundance and toxicity must be addressed because many of the highest performing cells contain toxic elements, such as $\mathrm{Cd}$ and $\mathrm{Pb}$. At the same time, the 'safer' alternatives found themselves unable to compete with the performances of the next-generation solar cells. Although many have shifted to a 'newer' generation of solar cell architectures, including organic, perovskite, and sensitized cells, the fully inorganic solar cells are still massively explored and experimented. Optimizations in various aspects can always be done, including the nanostructure dimension and spacing in the vertically aligned nanostructures, suitable doping, post-and treatment processes. With proper adjustments, the fully inorganic solar cells have the potential to be a promising candidate for a low-cost, reproducible photovoltaic device.

To date, the blend of PCBM and P3HT remains the most widely used blend of an active layer in OSCs. However, the combination of the two is not necessarily the best for achieving maximum efficiency, particularly due to the small energy difference between the PCBM's LUMO and P3HT's HOMO. As discussed in this review, a change in the material that can enlarge the difference between the two energies is necessary to improve the efficiency, which has been demonstrated by substituting PCBM with ICBA, or even with other non-fullerene derivatives. Optimization of the $\mathrm{ZnO} \mathrm{CBL}$, ranging from the favourable morphology of the 1D nanostructure, to details such as the nanorod/nanowire length, is also an important factor to determine the final performance. Nevertheless, many agreed that the utilization of $\mathrm{ZnO} \mathrm{CBL}$ is one of the most promising ways to achieve more efficient, more stable, and more reproducible OSCs, due to its favourable energy levels, possibility to provide an ohmic contact, excellent stability, as well as ease of synthesis and low cost. OSCs made by incorporating $\mathrm{ZnO}$ as CBL, particularly the ones with inverted structure, is quickly becoming a very promising solution to fabricate a low-cost, high performance and high stability photovoltaic device.

So far, reports of $\mathrm{ZnO} /$ organic HSCs performances are still lower than those of OSCs, especially against the PCBM/polymer based OSCs. Although the inorganic phase has been theorized to exhibit higher electron mobility, in practice, it does not always translate to higher performance due to several other factors mentioned before. Lower current densities are usually found across HSCs when compared to OSCs due to the poor polymer infiltration in the nanostructure, low polymer/ZnO wettability, and the small interfacial area between donor and acceptor. Low charge carrier mobility is also observed in HSCs utilizing P3HT as the organic component. P3HT was used due to its exceptional performance in PCBM/P3HT OSCs. However, the morphology of $\mathrm{ZnO}$ in the active layer may confine the P3HT, which may lead to much lower hole mobility, resulting in low PCE of the HSCs. Similar findings were also reported with MDMO-PPV as an organic semiconductor. Thus, it may be another topic of interest to couple $\mathrm{ZnO}$ nanostructures with another less explored p-type organic semiconductors. In the specific case of randomly dispersed nanocrystal solar cell architecture, the random dispersion of ZnO nanocrystals may be attributed to the reduced current density due to the unavailability of a direct electron transport pathway. Additional problems may arise when utilizing pre-synthesized nc-ZnO, in which solvent evaporation during synthesis may cause $\mathrm{ZnO}$ nanocrystals to agglomerate, reducing the current density even further down. The bilayer structure suffers mainly from a small interfacial area between the two phases. Although theoretically, the vertically aligned structures are the most ideal configuration for this application due to the structure's ability to provide a direct pathway for charge carrier collection, reports regarding this particular architecture so far have been relatively modest. This is particularly due to the low polymer infiltration and crystallinity, which can be relatively low even after thermal annealing, as well as unoptimized properties, such as unfavourable nanostructure morphologies. However, with proper morphology control (e.g., the spacing between nanorods should match the exciton diffusion length of the polymer, optimized nanorod/nanowire length), as well as the optimized blocking layer thickness, it is believed that cells made with this architecture can still be optimized and improved immensely in the future.

Despite many signs of progress achieved so far in terms of $\mathrm{ZnO}$ development, there is still plenty of room for improvement. Fig. 3 depicts the major challenges that need to be overcome for $\mathrm{ZnO}$ to be superior in solar cell applications. A higher surface area and light-harvesting ability are among the critical properties that need to be improved. In terms of the solar cell systems, the interface should be more effective than the current progress. Overall, these improvements would lead to a higher powerconversion efficiency and longer lifetime in various environments with a different thermal condition, humidity, and mechanical loading.

In general, emerging solar cell technologies are considered to have low penetration into the market. Thus, progress in achieving a low-cost technique to prepare $\mathrm{ZnO}$ with good reproducibility alongside a green method that provides sustainability and environmental-friendliness will boost the positive impacts on the socio-economic aspects. Besides, the capability of the whole device to be easily adjusted for various 
device requirements (flexible, wearable, durable, washable, etc.) is also vital for enhancing the commercialization.

\section{Conflicts of interest}

There are no conflicts to declare.

\section{Acknowledgements}

L. J. D. and M. I. A. would like to acknowledge the support from Universitas Prasetiya Mulya and the Indonesian Ministry of Research, Technology and Higher Education through INSINAS RISET PRATAMA (No. 47/INS-1/PPK/E4/2018 and No. 35/INS-1/ PPK/E4/2019) funding schemes. A. W. would like to acknowledge the funding provided by Institut Teknologi Bandung through ITB Research Fund, Research Group B 2020 (PN-6-012020).

\section{Notes and references}

1 R. Senger and K. Bajaj, Phys. Rev. B: Condens. Matter, 2003, 68, 045313.

2 G. Oskam, Z. Hu, R. L. Penn, N. Pesika and P. C. Searson, Phys. Rev. E, 2002, 66, 011403.

3 D. C. Look, D. C. Reynolds, J. Sizelove, R. Jones, C. W. Litton, G. Cantwell and W. Harsch, Solid State Commun., 1998, 105, 399-401.

4 J. Albrecht, P. Ruden, S. Limpijumnong, W. Lambrecht and K. Brennan, J. Appl. Phys., 1999, 86, 6864-6867.

5 W. I. Park, J. S. Kim, G.-C. Yi, M. Bae and H.-J. Lee, Appl. Phys. Lett., 2004, 85, 5052-5054.

6 H. Tang, K. Prasad, R. Sanjines, P. Schmid and F. Levy, J. Appl. Phys., 1994, 75, 2042-2047.

7 V. Noack, H. Weller and A. Eychmüller, J. Phys. Chem. B, 2002, 106, 8514-8523.

8 J.-J. Wu, G.-R. Chen, C.-C. Lu, W.-T. Wu and J.-S. Chen, Nanotechnology, 2008, 19, 105702.

9 M. Grätzel, Nature, 2001, 414, 338-344.

10 A. J. Nozik, Phys. E, 2002, 14, 115-120.

11 R. D. Schaller and V. I. Klimov, Phys. Rev. Lett., 2004, 92, 186601.

12 I. Robel, V. Subramanian, M. Kuno and P. V. Kamat, J. Am. Chem. Soc., 2006, 128, 2385-2393.

13 R. Plass, S. Pelet, J. Krueger, M. Grätzel and U. Bach, J. Phys. Chem. B, 2002, 106, 7578-7580.

14 O. Niitsoo, S. K. Sarkar, C. Pejoux, S. Rühle, D. Cahen and G. Hodes, J. Photochem. Photobiol., A, 2006, 181, 306-313.

15 L. J. Diguna, Q. Shen, J. Kobayashi and T. Toyoda, Appl. Phys. Lett., 2007, 91, 023116.

16 L. J. Diguna, M. Murakami, A. Sato, Y. Kumagai, T. Ishihara, N. Kobayashi, Q. Shen and T. Toyoda, Jpn. J. Appl. Phys., 2006, 45, 5563.

17 M. Matsumura, S. Matsudaira, H. Tsubomura, M. Takata and H. Yanagida, Ind. Eng. Chem. Prod. Res. Dev., 1980, 19, 415-421.
18 H. Rensmo, K. Keis, H. Lindström, S. Södergren, A. Solbrand, A. Hagfeldt, S.-E. Lindquist, L. Wang and M. Muhammed, J. Phys. Chem. B, 1997, 101, 2598-2601.

19 K. Hara, T. Horiguchi, T. Kinoshita, K. Sayama, H. Sugihara and H. Arakawa, Sol. Energy Mater. Sol. Cells, 2000, 64, 115134.

20 H. Horiuchi, R. Katoh, K. Hara, M. Yanagida, S. Murata, H. Arakawa and M. Tachiya, J. Phys. Chem. B, 2003, 107, 2570-2574.

21 K. Keis, J. Lindgren, S.-E. Lindquist and A. Hagfeldt, Langmuir, 2000, 16, 4688-4694.

22 G. A. Parks, Chem. Rev., 1965, 65, 177-198.

23 K. Keis, E. Magnusson, H. Lindström, S.-E. Lindquist and A. Hagfeldt, Sol. Energy Mater. Sol. Cells, 2002, 73, 51-58.

24 K. Keis, C. Bauer, G. Boschloo, A. Hagfeldt, K. Westermark, H. Rensmo and H. Siegbahn, J. Photochem. Photobiol., A, 2002, 148, 57-64.

25 K. Keis, L. Vayssieres, H. Rensmo, S.-E. Lindquist and A. Hagfeldt, J. Electrochem. Soc., 2001, 148, A149.

26 M. Law, L. E. Greene, J. C. Johnson, R. Saykally and P. Yang, Nat. Mater., 2005, 4, 455-459.

27 M. Law, L. E. Greene, A. Radenovic, T. Kuykendall, J. Liphardt and P. Yang, J. Phys. Chem. B, 2006, 110, 22652-22663.

28 Q. Zhao, T. Xie, L. Peng, Y. Lin, P. Wang, L. Peng and D. Wang, J. Phys. Chem. C, 2007, 111, 17136-17145.

29 Y. Hsu, Y. Xi, A. Djurišić and W. Chan, Appl. Phys. Lett., 2008, 92, 133507.

30 Z. Chen, Y. Tang, C. Liu, Y. Leung, G. Yuan, L. Chen, Y. Wang, I. Bello, J. Zapien and W. Zhang, J. Phys. Chem. C, 2009, 113, 13433-13437.

31 S. Yun, J. Lee, J. Chung and S. Lim, J. Phys. Chem. Solids, 2010, 71, 1724-1731.

32 J. Han, F. Fan, C. Xu, S. Lin, M. Wei, X. Duan and Z. L. Wang, Nanotechnology, 2010, 21, 405203.

33 A. B. Martinson, J. W. Elam, J. T. Hupp and M. J. Pellin, Nano Lett., 2007, 7, 2183-2187.

34 R. Vittal and K.-C. Ho, Renewable Sustainable Energy Rev., 2017, 70, 920-935.

35 D. Pourjafari and G. Oskam, in Nanomaterials for Solar Cell Applications, Elsevier, 2019, pp. 145-204.

36 Y.-K. Syu, Y. Tingare, C.-Y. Yeh, J.-S. Yang and J.-J. Wu, RSC Adv., 2016, 6, 59273-59279.

37 K. Funabiki, H. Mase, A. Hibino, N. Tanaka, N. Mizuhata, Y. Sakuragi, A. Nakashima, T. Yoshida, Y. Kubota and M. Matsui, Energy Environ. Sci., 2011, 4, 2186-2192.

38 P. K. Baviskar, D. P. Dubal, S. Majumder, A. Ennaoui and B. R. Sankapal, J. Photochem. Photobiol., A, 2016, 318, 135141.

39 D. Barpuzary, A. S. Patra, J. V. Vaghasiya, B. G. Solanki, S. S. Soni and M. Qureshi, ACS Appl. Mater. Interfaces, 2014, 6, 12629-12639.

40 I. Karki, J. Nakarmi, P. Mandal and S. Chatterjee, Appl. Sol. Energy, 2013, 49, 40-45.

41 C.-P. Lee, C.-T. Li, M.-S. Fan, S.-R. Li, Y.-J. Huang, L.-Y. Chang, C.-M. Tseng, S.-S. Sun, J.-J. Lin and K.-C. Ho, Electrochim. Acta, 2016, 210, 483-491. 
42 G.-J. Chang, S.-Y. Lin and J.-J. Wu, Nanoscale, 2014, 6, 13291334.

43 S.-Y. Lin and J.-J. Wu, Electrochim. Acta, 2015, 152, 61-67. 44 G. S. Selopal, H.-P. Wu, J. Lu, Y.-C. Chang, M. Wang, A. Vomiero, I. Concina and E. W.-G. Diau, Sci. Rep., 2016, 6, 18756.

45 J. X. Zhao, Y. Z. Zheng, X. H. Lu, J. F. Chen, X. Tao and W. Zhou, ChemPhysChem, 2013, 14, 1977-1984.

46 K. Mahmood and S. B. Park, J. Mater. Chem. A, 2013, 1, 4826-4835.

47 M. Lanjewar and J. V. Gohel, Inorg. Nano-Met. Chem., 2017, 47, 1090-1096.

48 S. Aksoy, O. Polat, K. Gorgun, Y. Caglar and M. Caglar, Phys. $E, 2020,121,114127$.

49 S. Goel, N. Sinha, H. Yadav, A. J. Joseph and B. Kumar, Phys. E, 2017, 91, 72-81.

50 A. K. Rajan and L. Cindrella, Superlattices Microstruct., 2019, 128, 14-22.

51 R. K. Chava and M. Kang, J. Alloys Compd., 2017, 692, 67-76. 52 A. Saboor, S. M. Shah and H. Hussain, Mater. Sci. Semicond. Process., 2019, 93, 215-225.

53 R. Chauhan, M. Shinde, A. Kumar, S. Gosavi and D. P. Amalnerkar, Microporous Mesoporous Mater., 2016, 226, 201-208.

54 T. Marimuthu, N. Anandhan and R. Thangamuthu, Appl. Surf. Sci., 2018, 428, 385-394.

55 C.-P. Lee, C.-Y. Chou, C.-Y. Chen, M.-H. Yeh, L.-Y. Lin, R. Vittal, C.-G. Wu and K.-C. Ho, J. Power Sources, 2014, 246, 1-9.

56 Q. Shen, J. Kobayashi, L. J. Diguna and T. Toyoda, J. Appl. Phys., 2008, 103, 084304.

57 P. Yu, K. Zhu, A. G. Norman, S. Ferrere, A. J. Frank and A. J. Nozik, J. Phys. Chem. B, 2006, 110, 25451-25454.

58 S. Giménez, I. Mora-Seró, L. Macor, N. Guijarro, T. LanaVillarreal, R. Gómez, L. J. Diguna, Q. Shen, T. Toyoda and J. Bisquert, Nanotechnology, 2009, 20, 295204.

59 G. Zhu, T. Lv, L. Pan, Z. Sun and C. Sun, J. Alloys Compd., 2011, 509, 362-365.

60 K. S. Leschkies, R. Divakar, J. Basu, E. Enache-Pommer, J. E. Boercker, C. B. Carter, U. R. Kortshagen, D. J. Norris and E. S. Aydil, Nano Lett., 2007, 7, 1793-1798.

61 Y. Choi, M. Seol, W. Kim and K. Yong, J. Phys. Chem. C, 2014, 118, 5664-5670.

62 T. Majumder, S. Dhar, P. Chakraborty, K. Debnath and S. P. Mondal, J. Electroanal. Chem., 2018, 813, 92-101.

63 L. Luo, G. Lv, B. Li, X. Hu, L. Jin, J. Wang and Y. Tang, Thin Solid Films, 2010, 518, 5146-5152.

64 L. J. Diguna, Q. Shen, A. Sato, K. Katayama, T. Sawada and T. Toyoda, Mater. Sci. Eng. C, 2007, 27, 1514-1520.

65 J. Luo, Y. X. Wang, J. Sun, Z. S. Yang and Q. F. Zhang, Sol. Energy Mater. Sol. Cells, 2018, 187, 199-206.

66 L. Yu and Z. Li, Nanomaterials, 2019, 9, 132.

67 Z. Li, L. Yu, H. Wang, H. Yang and H. Ma, Nanomaterials, 2020, 10, 631.

68 K. Žídek, M. Abdellah, K. Zheng and T. Pullerits, Sci. Rep., 2014, 4, 1-8.
69 O. E. Semonin, J. M. Luther, S. Choi, H.-Y. Chen, J. Gao, A. J. Nozik and M. C. Beard, Science, 2011, 334, 1530-1533.

70 V. Chakrapani, D. Baker and P. V. Kamat, J. Am. Chem. Soc., 2011, 133, 9607-9615.

71 J. Duan, Q. Tang, Y. Sun, B. He and H. Chen, RSC Adv., 2014, 4, 60478-60483.

72 M. Eskandari, R. Ghahary, M. Shokri and V. Ahmadi, RSC Adv., 2016, 6, 51894-51899.

73 C. V. Gopi, M. Venkata-Haritha, Y.-S. Lee and H.-J. Kim, J. Mater. Chem. A, 2016, 4, 8161-8171.

74 S. Yun, Y. Qin, A. R. Uhl, N. Vlachopoulos, M. Yin, D. Li, X. Han and A. Hagfeldt, Energy Environ. Sci., 2018, 11, 476-526.

75 N. G. Park, Adv. Energy Mater., 2020, 10, 1903106.

76 N. A. N. Ouedraogo, Y. Chen, Y. Y. Xiao, Q. Meng, C. B. Han, H. Yan and Y. Zhang, Nano Energy, 2020, 67, 104249.

77 J. A. Schwenzer, L. Rakocevic, T. Abzieher, D. RuedaDelgado, S. Moghadamzadeh, S. Gharibzadeh, I. M. Hossain, R. Gehlhaar, B. S. Richards and U. Lemmer, IEEE Journal of Photovoltaics, 2020, 10, 777-784.

78 A. Kojima, K. Teshima, Y. Shirai and T. Miyasaka, J. Am. Chem. Soc., 2009, 131, 6050-6051.

79 J. Zhao, X. Zheng, Y. Deng, T. Li, Y. Shao, A. Gruverman, J. Shield and J. Huang, Energy Environ. Sci., 2016, 9, 36503656.

80 T. Pauportè, in The Future of Semiconductor Oxides in NextGeneration Solar Cells, Elsevier, 2018, pp. 3-43.

81 J. Luo, Y. Wang and Q. Zhang, Sol. Energy, 2018, 163, 289306.

82 G. Yang, H. Tao, P. Qin, W. Ke and G. Fang, J. Mater. Chem. A, 2016, 4, 3970-3990.

83 D. Liu and T. L. Kelly, Nat. Photonics, 2014, 8, 133-138.

84 X. Yang, R. Wang, C. Fan, G. Li, Z. Xiong and G. E. Jabbour, Org. Electron., 2014, 15, 2387-2394.

85 L. Zuo, Z. Gu, T. Ye, W. Fu, G. Wu, H. Li and H. Chen, J. Am. Chem. Soc., 2015, 137, 2674-2679.

86 E. Zheng, Y. Wang, J. Song, X.-F. Wang, W. Tian, G. Chen and T. Miyasaka, J. Energy Chem., 2018, 27, 1461-1467.

87 J. Duan, Q. Xiong, H. Wang, J. Zhang and J. Hu, J. Mater. Sci.: Mater. Electron., 2017, 28, 60-66.

88 K. Mahmood, B. S. Swain and A. Amassian, Adv. Energy Mater., 2015, 5, 1500568.

89 S. Li, P. Zhang, H. Chen, Y. Wang, D. Liu, J. Wu, H. Sarvari and Z. D. Chen, J. Power Sources, 2017, 342, 990-997.

90 S. Zhuiykov, in Nanostructured semiconductor oxides for the next generation of electronics and functional devices: properties and applications, Woodhead Publishing, 2014.

91 D. P. Norton, Y. Heo, M. Ivill, K. Ip, S. Pearton, M. F. Chisholm and T. Steiner, Mater. Today, 2004, 7, 34-40.

92 Y.-Z. Zheng, E.-F. Zhao, F.-L. Meng, X.-S. Lai, X.-M. Dong, J.-J. Wu and X. Tao, J. Mater. Chem. A, 2017, 5, 12416-12425.

93 K. Mahmood and S. B. Park, Electron. Mater. Lett., 2013, 9, 161-170.

94 Y. Chen, Y. Hu, Q. Meng, H. Yan, W. Shuai and Z. Zhang, J. Mater. Sci.: Mater. Electron., 2019, 30, 4726-4736.

95 J. Dong, J. Shi, D. Li, Y. Luo and Q. Meng, Appl. Phys. Lett., 2015, 107, 073507. 
96 J. Dong, Y. Zhao, J. Shi, H. Wei, J. Xiao, X. Xu, J. Luo, J. Xu, D. Li and Y. Luo, ChemComm, 2014, 50, 13381-13384.

97 N. Shibayama, H. Kanda, S.-i. Yusa, S. Fukumoto, A. K. Baranwal, H. Segawa, T. Miyasaka and S. Ito, Nano Convergence, 2017, 4, 1-5.

98 M. Dehghan and A. Behjat, RSC Adv., 2019, 9, 20917-20924.

99 Y. Xu, T. Liu, Z. Li, B. Feng, S. Li, J. Duan, C. Ye, J. Zhang and H. Wang, Appl. Surf. Sci., 2016, 388, 89-96.

100 S. Li, P. Zhang, Y. Wang, H. Sarvari, D. Liu, J. Wu, Y. Yang, Z. Wang and Z. D. Chen, Nano Res., 2017, 10, 1092-1103.

101 X. Dong, H. Hu, B. Lin, J. Ding and N. Yuan, ChemComm, 2014, 50, 14405-14408.

102 L. Kazmerski, F. White and G. Morgan, Appl. Phys. Lett., 1976, 29, 268-270.

103 M. Zhong, L. Chai and Y. Wang, Appl. Surf. Sci., 2019, 464, 301-310.

104 C. K. Miskin, S. D. Deshmukh, V. Vasiraju, K. Bock, G. Mittal, A. Dubois-Camacho, S. Vaddiraju and R. Agrawal, ACS Appl. Nano Mater., 2019, 2, 1242-1252.

105 K. S. Leschkies, T. J. Beatty, M. S. Kang, D. J. Norris and E. S. Aydil, ACS Nano, 2009, 3, 3638-3648.

106 J. M. Luther, J. Gao, M. T. Lloyd, O. E. Semonin, M. C. Beard and A. J. Nozik, Adv. Mater., 2010, 22, 3704-3707.

107 N. M. Rosas-Laverde, A. Pruna, J. Cembrero, J. OrozcoMessana and F. J. Manjón, Bol. Soc. Esp. Ceram. Vidrio, 2019, 58, 263-273.

108 R. Gayen and T. Chakrabarti, Mater. Sci. Semicond. Process., 2019, 100, 1-7.

109 S. Qiao, J. Liu, G. Fu, K. Ren, Z. Li, S. Wang and C. Pan, Nano Energy, 2018, 49, 508-514.

110 Z. Zang, Appl. Phys. Lett., 2018, 112, 042106.

111 T. Minami, T. Miyata and Y. Nishi, Thin Solid Films, 2014, 559, 105-111.

112 T. Minami, Y. Nishi and T. Miyata, Appl. Phys. Express, 2013, 6, 044101.

113 U. Ozgur, D. Hofstetter and H. Morkoc, Proceedings of the IEEE, 2010, 98, 1255-1268.

114 D.-C. Perng, M.-H. Hong, K.-H. Chen and K.-H. Chen, J. Alloys Compd., 2017, 695, 549-554.

115 J. Jean, S. Chang, P. R. Brown, J. J. Cheng, P. H. Rekemeyer, M. G. Bawendi, S. Gradečak and V. Bulović, Adv. Mater., 2013, 25, 2790-2796.

116 H. Wang, T. Kubo, J. Nakazaki and H. Segawa, ACS Energy Lett., 2017, 2, 2110-2117.

117 A. Tamang, M. Pathirane, R. Parsons, M. M. Schwarz, B. Iheanacho, V. Jovanov, V. Wagner, W. S. Wong and D. Knipp, Opt. Express, 2014, 22, A622-A632.

118 B. Wang, X. Zhu, S. Li, M. Chen, N. Liu, H. Yang, M. Ran, H. Lu and Y. Yang, Nanomaterials, 2019, 9, 1263.

119 L. Zhu, L. Wang, F. Xue, L. Chen, J. Fu, X. Feng, T. Li and Z. L. Wang, Adv. Sci., 2017, 4, 1600185.

120 M. A. Akram, S. Javed, M. Islam, M. Mujahid and A. Safdar, Sol. Energy Mater. Sol. Cells, 2016, 146, 121-128.

121 E. Peksu and H. Karaagac, J. Nanomater., 2015, 2015, 516012 .

122 K. Yamada, N. Hoshino and T. Nakada, Sci. Technol. Adv. Mater., 2006, 7, 42.
123 F.-I. Lai, J.-F. Yang, W.-X. Liao and S.-Y. Kuo, Sci. Rep., 2017, 7, 1-9.

124 X. Pu, J. Liu, J. Liang, Y. Xia, W. Feng, Y. Wang and X. Yu, RSC Adv., 2014, 4, 23149-23154.

125 L. Wang, D.-B. Li, K. Li, C. Chen, H.-X. Deng, L. Gao, Y. Zhao, F. Jiang, L. Li and F. Huang, Nat. Energy, 2017, 2, 1-9.

126 J. Yang, J. Lee, J. Lee and W. Yi, J. Power Sources, 2019, 421, 124-131.

127 D. Said, A. Ali, M. Khayyat, M. Boustimi, M. Loulou and R. Seoudi, Heliyon, 2019, 5, e02675.

128 T. Kawawaki, H. Wang, T. Kubo, K. Saito, J. Nakazaki, H. Segawa and T. Tatsuma, ACS Nano, 2015, 9, 4165-4172.

129 F. Yang, Y. Xu, M. Gu, S. Zhou, Y. Wang, K. Lu, Z. Liu, X. Ling, Z. Zhu and J. Chen, J. Mater. Chem. A, 2018, 6, 17688-17697.

130 K. Li, R. Kondrotas, C. Chen, S. Lu, X. Wen, D. Li, J. Luo, Y. Zhao and J. Tang, Sol. Energy, 2018, 167, 10-17.

131 A. Kaphle, E. Echeverria, D. N. Mcllroy and P. Hari, RSC Adv., 2020, 10, 7839-7854.

132 Y.-K. Hsu, H.-H. Lin, J.-R. Wu, M.-H. Chen, Y.-C. Chen and Y.-G. Lin, RSC Adv., 2014, 4, 7655-7659.

133 S. Zang, Y. Wang, M. Li, W. Su, H. Zhu, X. Zhang and Y. Liu, Sol. Energy Mater. Sol. Cells, 2017, 169, 264-269.

134 C.-H. M. Chuang, P. R. Brown, V. Bulović and M. G. Bawendi, Nat. Mater., 2014, 13, 796-801.

135 S. Paulo, E. Palomares and E. Martinez-Ferrero, Nanomaterials, 2016, 6, 157.

136 H. Y. Abbasi, A. Habib and M. Tanveer, J. Alloys Compd., 2017, 690, 21-26.

137 V. González, I. López, R. M. Palma, Y. Peña and I. Gómez, Mater. Res. Express, 2020, 7, 075005.

138 M. A. Halim, Nanomaterials, 2013, 3, 22-47.

139 J. Huang, Z. Yin and Q. Zheng, Energy Environ. Sci., 2011, 4, 3861-3877.

140 W. J. Beek, M. M. Wienk and R. A. Janssen, Adv. Mater., 2004, 16, 1009-1013.

141 Y. Hames, Z. Alpaslan, A. Kösemen, S. E. San and Y. Yerli, Sol. Energy, 2010, 84, 426-431.

142 J. Liu, S. Wang, Z. Bian, M. Shan and C. Huang, Appl. Phys. Lett., 2009, 94, 173107.

143 S. Dayal, N. Kopidakis, D. C. Olson, D. S. Ginley and G. Rumbles, Nano Lett., 2010, 10, 239-242.

144 J. Qi, J. Chen, W. Meng, X. Wu, C. Liu, W. Yue and M. Wang, Synth. Met., 2016, 222, 42-65.

145 W. J. Beek, M. M. Wienk and R. A. Janssen, Adv. Funct. Mater., 2006, 16, 1112-1116.

146 L. J. A. Koster, W. J. van Strien, W. J. Beek and P. W. Blom, Adv. Funct. Mater., 2007, 17, 1297-1302.

147 S. D. Oosterhout, M. M. Wienk, S. S. Van Bavel, R. Thiedmann, L. J. A. Koster, J. Gilot, J. Loos, V. Schmidt and R. A. Janssen, Nat. Mater., 2009, 8, 818-824.

148 S.-S. Li and C.-W. Chen, J. Mater. Chem. A, 2013, 1, 1057410591.

149 W. J. Beek, L. H. Slooff, M. M. Wienk, J. M. Kroon and R. A. Janssen, Adv. Funct. Mater., 2005, 15, 1703-1707. 
150 W. J. Beek, M. M. Wienk, M. Kemerink, X. Yang and R. A. Janssen, J. Phys. Chem. B, 2005, 109, 9505-9516.

151 D. J. Moet, L. J. A. Koster, B. de Boer and P. W. Blom, Chem. Mater., 2007, 19, 5856-5861.

152 A. Thomas, R. Vinayakan and V. Ison, $R S C A d v ., 2020,10$, 16693-16699.

153 P. Ravirajan, A. M. Peiró, M. K. Nazeeruddin, M. Graetzel, D. D. Bradley, J. R. Durrant and J. Nelson, J. Phys. Chem. $B, 2006,110,7635-7639$.

154 I. Gonzalez-Valls and M. Lira-Cantu, Energy Environ. Sci., 2009, 2, 19-34.

155 S. Jung, J. Lee, J. Seo, U. Kim, Y. Choi and H. Park, Nano Lett., 2018, 18, 1337-1343.

156 J. Pei, K. Feng, X. Zhao, Y. Hao, Y. Wei, B. Sun, Y. Li, S. Chen and H. Lv, Opt. Commun., 2018, 427, 294-300.

157 A. Galdámez-Martinez, G. Santana, F. Güell, P. R. MartínezAlanis and A. Dutt, Nanomaterials, 2020, 10, 857.

158 D. C. Olson, J. Piris, R. T. Collins, S. E. Shaheen and D. S. Ginley, Thin Solid Films, 2006, 496, 26-29.

159 D. C. Olson, Y.-J. Lee, M. S. White, N. Kopidakis, S. E. Shaheen, D. S. Ginley, J. A. Voigt and J. W. Hsu, J. Phys. Chem. C, 2007, 111, 16640-16645.

160 L. Baeten, B. Conings, H. G. Boyen, J. D'Haen, A. Hardy, M. D'Olieslaeger, J. V. Manca and M. K. Van Bael, Adv. Mater., 2011, 23, 2802-2805.

161 C. Thu, P. Ehrenreich, K. K. Wong, E. Zimmermann, J. Dorman, W. Wang, A. Fakharuddin, M. Putnik, C. Drivas and A. Koutsoubelitis, Sci. Rep., 2018, 8, 1-8.

162 S. B. Dkhil, M. Gaceur, W. Dachraoui, D. Hannani, S. Fall, F. Brunel, M. Wang, G. Poize, J. Mawyin and I. Shupyk, Sol. Energy Mater. Sol. Cells, 2017, 159, 608-616.

163 A. Alshanableh, S. T. Tan, C. C. Yap, H. B. Lee, H. F. Oleiwi, K. J. Hong, M. H. H. Jumali and M. Yahaya, Mater. Sci. Eng., $B, 2018,238,136-141$.

164 J. Han, Z. Liu, X. Zheng, K. Guo, X. Zhang, T. Hong, B. Wang and J. Liu, RSC Adv., 2014, 4, 23807-23814.

165 D. C. Olson, Y.-J. Lee, M. S. White, N. Kopidakis, S. E. Shaheen, D. S. Ginley, J. A. Voigt and J. W. Hsu, J. Phys. Chem. C, 2008, 112, 9544-9547.

166 D. C. Olson, S. E. Shaheen, M. S. White, W. J. Mitchell, M. F. van Hest, R. T. Collins and D. S. Ginley, Adv. Funct. Mater., 2007, 17, 264-269.

167 A. Samavati, Z. Samavati, A. Ismail, M. Othman, M. A. Rahman and I. Amiri, RSC Adv., 2018, 8, 1418-1426.

168 M. S. White, D. C. Olson, N. Kopidakis, A. M. Nardes, D. S. Ginley and J. J. Berry, Phys. Status Solidi, 2010, 207, 1257-1265.

169 J. Bouclé, H. J. Snaith and N. C. Greenham, J. Phys. Chem. C, 2010, 114, 3664-3674.

170 D. C. Olson, S. E. Shaheen, R. T. Collins and D. S. Ginley, J. Phys. Chem. C, 2007, 111, 16670-16678.

171 M. Batmunkh, Y. L. Zhong and H. Zhao, Adv. Mater., 2020, 32, 2000631.

172 H.-L. Yip and A. K.-Y. Jen, Energy Environ. Sci., 2012, 5, 5994-6011.

173 A. Manor, E. A. Katz, T. Tromholt and F. C. Krebs, Sol. Energy Mater. Sol. Cells, 2012, 98, 491-493.
174 Y. Jouane, S. Colis, G. Schmerber, P. Kern, A. Dinia, T. Heiser and Y.-A. Chapuis, J. Mater. Chem., 2011, 21, 1953-1958.

175 T. C. Monson, M. T. Lloyd, D. C. Olson, Y. J. Lee and J. W. Hsu, Adv. Mater., 2008, 20, 4755-4759.

176 S. K. Hau, H.-L. Yip, N. S. Baek, J. Zou, K. O'Malley and A. K.-Y. Jen, Appl. Phys. Lett., 2008, 92, 225.

177 H. L. Yip, S. K. Hau, N. S. Baek, H. Ma and A. K. Y. Jen, Adv. Mater., 2008, 20, 2376-2382.

178 H.-L. Yip, S. K. Hau, N. S. Baek and A. K.-Y. Jen, Appl. Phys. Lett., 2008, 92, 179.

179 H. Cao, W. He, Y. Mao, X. Lin, K. Ishikawa, J. H. Dickerson and W. P. Hess, J. Power Sources, 2014, 264, 168-183.

180 Z. Liang, Q. Zhang, L. Jiang and G. Cao, Energy Environ. Sci., 2015, 8, 3442-3476.

181 Y.-J. Cheng, C.-H. Hsieh, Y. He, C.-S. Hsu and Y. Li, J. Am. Chem. Soc., 2010, 132, 17381-17383.

182 Y. He, H.-Y. Chen, J. Hou and Y. Li, J. Am. Chem. Soc., 2010, 132, 1377-1382.

183 S. Ganesan, S. R. Gollu, A. Kushwaha and D. Gupta, Opt. Mater., 2019, 94, 430-435.

184 C. M. Amb, S. Chen, K. R. Graham, J. Subbiah, C. E. Small, F. So and J. R. Reynolds, J. Am. Chem. Soc., 2011, 133, 10062-10065.

185 A. Djurišić, A. M. C. Ng and X. Chen, Prog. Quantum Electron., 2010, 34, 191-259.

186 K. Takanezawa, K. Hirota, Q.-S. Wei, K. Tajima and K. Hashimoto, J. Phys. Chem. C, 2007, 111, 7218-7223.

187 C.-Y. Chou, J.-S. Huang, C.-H. Wu, C.-Y. Lee and C.-F. Lin, Sol. Energy Mater. Sol. Cells, 2009, 93, 1608-1612.

188 R. B. Ambade, S. B. Ambade, R. S. Mane and S.-H. Lee, ACS Appl. Mater. Interfaces, 2015, 7, 7951-7960.

189 N. Sekine, C.-H. Chou, W. L. Kwan and Y. Yang, Org. Electron., 2009, 10, 1473-1477.

190 S. Y. Ryu, J. H. Seo, H. Hafeez, M. Song, J. Y. Shin, D. H. Kim, Y. C. Jung and C. S. Kim, J. Phys. Chem. C, 2017, 121, 9191-9201.

191 R. Thitima, C. Patcharee, S. Takashi and Y. Susumu, SolidState Electron., 2009, 53, 176-180.

192 Y. Vaynzof, D. Kabra, L. Zhao, P. K. Ho, A. T.-S. Wee and R. H. Friend, Appl. Phys. Lett., 2010, 97, 156.

193 C.-T. Chen, F.-C. Hsu, S.-W. Kuan and Y.-F. Chen, Sol. Energy Mater. Sol. Cells, 2011, 95, 740-744.

194 H. Ma, H. L. Yip, F. Huang and A. K. Y. Jen, Adv. Funct. Mater., 2010, 20, 1371-1388.

195 C.-H. Hsieh, Y.-J. Cheng, P.-J. Li, C.-H. Chen, M. Dubosc, R.-M. Liang and C.-S. Hsu, J. Am. Chem. Soc., 2010, 132, 4887-4893.

196 D. Zheng, W. Huang, P. Fan, Y. Zheng, J. Huang and J. Yu, ACS Appl. Mater. Interfaces, 2017, 9, 4898-4907.

197 S. R. Gollu, R. Sharma, G. Srinivas, S. Kundu and D. Gupta, Org. Electron., 2016, 29, 79-87.

198 J. Wei, G. Ji, C. Zhang, L. Yan, Q. Luo, C. Wang, Q. Chen, J. Yang, L. Chen and C.-Q. Ma, ACS Nano, 2018, 12, 55185529.

199 Y. Cao, D. Wu, P. Zhu, D. Shan, X. Zeng and J. Xu, Nanomaterials, 2020, 10, 775. 
200 F. Bu, W. Shen, X. Zhang, Y. Wang, L. A. Belfiore and J. Tang, Nanomaterials, 2020, 10, 80.

201 W. Shen, G. Zhao, X. Zhang, F. Bu, J. Yun and J. Tang, Nanomaterials, 2020, 10, 944.

202 K.-S. Shin, K.-H. Lee, H. H. Lee, D. Choi and S.-W. Kim, J. Phys. Chem. C, 2010, 114, 15782-15785.

203 A. K. K. Kyaw, X. Sun, S. T. Tan, Y. Divayana and H. V. Demir, IEEE J. Sel. Top. Quantum Electron., 2010, 16, 1700-1706.

204 M. Zafar, B. Kim and D.-H. Kim, Mater. Chem. Phys., 2020, 240, 122076.

205 G. Chen, T. Wang, C. Li, L. Yang, T. Xu, W. Zhu, Y. Gao and B. Wei, Org. Electron., 2016, 36, 50-56.

206 M. Ramírez-Como, V. Balderrama, A. Sacramento, L. Marsal, G. Lastra and M. Estrada, Sol. Energy, 2019, 181, 386-395.
207 M.-S. White, D. Olson, S. Shaheen, N. Kopidakis and D. S. Ginley, Appl. Phys. Lett., 2006, 89, 143517.

208 T. Yang, W. Cai, D. Qin, E. Wang, L. Lan, X. Gong, J. Peng and Y. Cao, J. Phys. Chem. C, 2010, 114, 6849-6853.

209 W. Zhao, S. Zhang and J. Hou, Sci. China: Chem., 2016, 59, 1574-1582.

210 X. Li, X. Liu, W. Zhang, H.-Q. Wang and J. Fang, Chem. Mater., 2017, 29, 4176-4180.

211 X. Wen, A. Nowak-Król, O. Nagler, F. Kraus, N. Zhu, N. Zheng, M. Müller, D. Schmidt, Z. Xie and F. Würthner, Angew. Chem., 2019, 131, 13185-13189.

212 N. Shrivastava, H. Barbosa, K. Ali and S. K. Sharma, in Solar Cells - From Material to Device Technology, Springer International Publishing, 2020, pp. 55-78. 